\title{
SUPPORT VECTOR MACHINES IN STRUCTURAL ENGINEERING: A REVIEW
}

\author{
Abdulkadir ÇEVİK ${ }^{\mathrm{a}}$, Ahmet Emin KURTOĞLU ${ }^{\mathrm{b}}$, Mahmut BİLGEHAN ${ }^{\mathrm{b}}$, \\ Mehmet Eren GÜLŞAN ${ }^{\mathrm{a}}$, Hasan M. ALBEGMPRLI ${ }^{\mathrm{c}}$ \\ ${ }^{a}$ Department of Civil Engineering, University of Gaziantep, 27310, Gaziantep, Turkey \\ ${ }^{b}$ Department of Civil Engineering, Zirve University, Kizilhisar Campus, 27260, Gaziantep, Turkey \\ ${ }^{c}$ Technical College of Mosul, Foundation of Technical Education, Iraq
}

Received 17 Oct 2014; accepted 12 Nov 2014

\begin{abstract}
Recent development in data processing systems had directed study and research of engineering towards the creation of intelligent systems to evolve models for a wide range of engineering problems. In this respect, several modeling techniques have been created to simulate various civil engineering systems. This study aims to review the studies on support vector machines (SVM) in structural engineering and investigate the usability of this machine learning based approach by providing three case studies focusing on structural engineering problems. Firstly, the concept of SVM is explained and then, the recent studies on the application of SVM in structural engineering are summarized and discussed. Next, we performed three case studies using the experimental studies provided. Applicability of SVM in structural engineering is confirmed by these case studies. The results showed that SVM is superior to various other learning techniques considering the generalization capability of produced model.
\end{abstract}

Keywords: support vector machines, statistical learning, structural engineering, ultimate load capacity, FRP reinforcement, SFRC corbels, haunched beams.

\section{Introduction}

Recent advance in data modeling technology has drawn great attention from various engineering practices. As a result, empirical data modeling is becoming more significant to researchers and engineers in practice. Thus, a process of data training is used to create a model of a system for the purpose of obtaining predictions for the cases that are yet to be observed. The model performance, therefore, is largely dependent on the quantity and the accuracy of experimental findings used for training the model. Being a new modeling technique, support vector machines approach (SVM) is one of those methods that can be implemented to predict test results.

In structural engineering, empirical data modeling is of great concern as it helps researchers and engineers to predict test results. That is, this research attempts to investigate the applicability of this novel approach to structural engineering problems. This paper has five parts. First, it explains the historical development and the key principals of support vector machines (SVM). Then, the applications of SVM on various structural engineering problems are reviewed. Next, three case studies are performed to confirm the performance of SVM. The paper concludes with a discussion of provided case studies' re- sults and applicability of this new approach on structural engineering problems.

\section{Support vector machines as a modeling tool}

SVMs were first formulated and presented by Boser, Guyon and Vapnik (Boser et al. 1992), and were presented for the first time at the Computational Learning Theory (COLT) conference in 1992. Main characteristics of the approach were already available in the literature and were applied in machine learning like large margin hyper planes in the input space since the 1960s (Cristianini, Shawe-Taylor 2000).

After being presented, many researchers have processed both the algorithmic and theoretical analysis of these systems, producing in just a few years what is efficiently a novel research path in its own right, merging subjects of scientific research areas such as statistics, optimization, functional analysis as well as machine learning. A few years later, Cortes and Vapnik (1995) presented the soft margin classifier. The algorithm was expanded to the regression case in 1995 (Vapnik 2000).

Besides its solid numerical basis in statistical learning theory, support vector machines have showed extremely competing performance in several applications,

Corresponding author: Abdulkadir Çevik

E-mail:akcevik@gantep.edu.tr 
e.g., face recognition, text mining, bioinformatics and image processing. This fact has proven that SVMs are one of the state-of-the-art approaches for data mining and machine learning, together with some other soft computing methods, e.g. fuzzy systems and neural networks (Wang 2005).

Being a controlled learning technique, the SVM yields input-output mapping functions from a set of labeled training data. Either a regression or a classification function, i.e. the category of the input data can be the mapping function. Nonlinear kernel functions, for classification, are frequently applied to convert input data to a high-dimensional feature space. By this way, the input data become more separable in comparison to the exact input space. Creation of maximum-margin hyper planes is then performed (Wang 2005).

By solving the optimization, the parametric quantities of the maximum-margin hyper plane are derived. There exist numerous specific algorithmic rules for the purpose of rapidly solving the QP problem that originates from SVMs, generally dependent on heuristic rules to break the problem down into smaller, more controllable portions. Piatt's SMO algorithm is a typical technique for solving the QP problem. This algorithm breaks the problem down into 2D sub-problems for the purpose of analytical analysis. Thus, the need for a numerical optimization algorithm, i.e. conjugate gradient method is eliminated.

The model then developed depending on solely a subset of the training data adjacent to the class boundaries. Likewise, the model created by Support Vector Regression neglects any training data that is adequately close to the model prediction. It is supposed that the SVMs are likewise belonging to "kernel techniques" (Wang 2005).

The development order of SVMs has been reverse to the evolution of NNs. SVMs were developed from the sound theory to the application and tests, while the $\mathrm{NNs}$ were accompanied by trial-and-error path, from implementations and considerable experimentation to the theory. Surprisingly, SVMs has not been widely appreciated at the beginning despite its very strong theoretical background. Nowadays, it is obvious that SVMs demonstrate better (or comparable) performance than neural networks and other statistical models, on solving the real world problems (Huang et al. 2006).

\subsection{Support vector classification}

SVMs are quite useful for data classification purposes. The classification process starts with separating data into training and testing sets. Each data row in training set includes a target value and several "attributes". The main purpose of SVM is to create a model which predicts the target values of the test data by using given attributes (Hsu et al. 2003). The kernel functions used for data classification are as follows:

- Linear:

$$
K\left(x_{i}, x_{j}\right)=x_{i}^{T} x_{j}
$$

- Polynomial:

$$
K\left(x_{i}, x_{j}\right)=\left(\gamma x_{i}^{T} x_{j}+r\right)^{d}, \gamma>0 ;
$$

- Radial Basis Function (RBF):

$$
K\left(x_{i}, x_{j}\right)=\exp \left(-\gamma\left\|x_{i}^{T} x_{j}\right\|^{2}\right), \gamma>0 ;
$$

- Sigmoid:

$$
K\left(x_{i}, x_{j}\right)=\tanh \left(\gamma x_{i}^{T} x_{j}+r\right) .
$$

where $\gamma, d$ and $r$ are kernel parameters.

Normally, the procedure of SVM includes:

1. Data transformation to the format of SVM package;

2. Trying $\gamma$ a few kernels and parameters on a random basis;

3. Testing the model.

Hsu et al. (2003) proposed a new SVM procedure as explained below:

1. Data transformation to the format of SVM package;

2. Application of simple scaling on data;

3. Consider RBF kernel function;

4. Obtain the values for parameters $C$ and $\gamma$ by using cross-validation;

5. Use obtained $C$ and $\gamma$ parameters to train the whole training set;

6. Testing the model.

\subsection{Support vector regression}

SVM were initially evolved for solving the classification problems. However, researchers started utilizing SVM to solve regression problems by preserving the entire maximal margin algorithm. A function named as-insensitive loss function that neglects errors that are inside a definite distance of the exact value is able to supervise a parametric quantity that is equal to the margin parameter for separating hyper planes. In SVR (support vector regression), for a given set of training data, the main goal to obtain a function that has maximum difference from the exact found targets for all the training data, and at the same time is at most flat, i.e. we do not focus on errors as long as they are less than, but any deviation larger than a certain amount is not acceptable (Chen et al. 2004). The (linear) insensitive loss function $L(x, y, f)$ is described as:

$$
L^{\varepsilon}(x, y, f)=|y-f(x)|_{\varepsilon}=\left\{\begin{array}{cc}
0 & \text { if }|y-f(x)| \leq \varepsilon \\
|y-f(x)|-\varepsilon & \text { otherwise }
\end{array},\right.
$$

where $f$ is a real-valued function on a $x$ and the quadratic $\varepsilon$-insensitive loss is defined by:

$$
L_{2}^{\varepsilon}(x, y, f)=|y-f(x)|_{\varepsilon}^{2} .
$$

Figure 1 illustrates the form of linear and quadratic $\varepsilon$-insensitive loss function for zero and non-zero $\varepsilon$.

The loss function $L(y, f(x, \omega))$ determines the performance of accuracy. Performing linear regression in the 


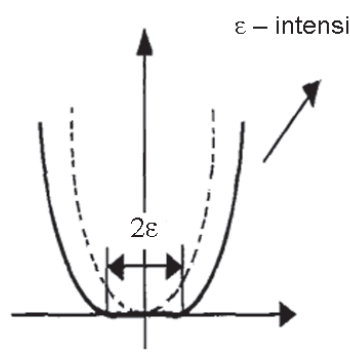

a) Quadratic

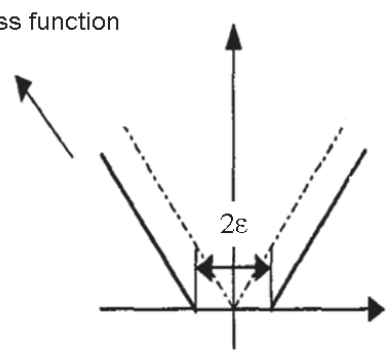

b) Linear

Fig. 1. The form of linear and quadratic $\varepsilon$-insensitive loss function for zero and non-zero $\varepsilon$

high-dimension feature space by the use of $\varepsilon$-insensitive loss function, SVM attempts to decrease model complexity by performing the minimization of $\|\omega\|^{2}$. By introducing (non-negative) slack variables $\xi_{j}, \xi_{i}^{*} i=1, . . n$ :

$$
\begin{aligned}
& L(y, f(x, \omega))=|y-f(x)|_{\varepsilon}^{2} \\
& L_{2}^{\varepsilon}(x, y, f)=|y-f(x)|_{\varepsilon}^{2}
\end{aligned}
$$

to determine the deviation of training data outside $\varepsilon-$ zone. Following formulation is utilized for the minimization of SVM regression:

$$
\begin{gathered}
\frac{1}{2}\|\omega\|^{2}+c \sum_{i=1}^{n}\left(\xi_{i+} \xi_{i}^{*}\right) \text { subject to } \xi_{j}, \xi_{i}^{*} i=1, . . n \\
\xi_{j}, \xi_{i}^{*} i=1, . . n .
\end{gathered}
$$

The solution of this optimization problem can be found by transforming it into the dual problem:

$$
\begin{aligned}
f(x)= & \sum_{i=1}^{n_{s v}}\left(\alpha_{j}-\alpha_{i}^{*}\right) K\left(x_{j}, x\right) \text { subject to } \\
& 0 \leq \alpha_{i}^{*} \leq C, 0 \leq \alpha_{j} \leq C
\end{aligned}
$$

where $n_{s v}$ is the number of support vectors (SVs) and $K\left(x_{j}, x\right)$ is a kernel function. Generalization capability (accuracy of estimation) of SVM is dependent on a proper setting of meta-parameters $C, \varepsilon$ and the kernel parameters. Current software applications usually allow users to define meta-parameters of SVM regression (Cherkassky, Ma 2002).

Parameter $C$ controls the exchange between the model complexity as well as the degree to which deviations larger than $\varepsilon$ are tolerated in optimization formulation. Parameter $\varepsilon$ describes the width of $\varepsilon$ - insensitive zone, which is utilized to fit the training data. The number of SVs used to create the regression function can be affected by the value of $\varepsilon$. The fewer SVs are obtained by choosing the bigger $\varepsilon$. On the other hand, greater $\varepsilon$-insensitive values cause more 'flat' predictions. Although in different ways, both $C$ and $\varepsilon$ values affect model complexity (flatness) (Cherkassky, Ma 2002).

There are numerous kernel functions for machine learning. In this study, four different kernel functions namely as linear, polynomial, radial basis and sigmoid functions are used:

- Linear kernel function:

$$
K\left(x_{i}, x\right)=x_{i} x
$$

- Polynomial kernel function:

$$
K\left(x_{i}, x\right)=\left(x_{i}(x+1)\right)^{d}
$$

- Radial basis function:

$$
K\left(x_{i}, x\right)=\exp \left[-\frac{\left(x_{i}-x\right)\left(x_{i}-x\right)}{2 \sigma^{2}}\right]
$$

- Sigmoid kernel function:

$$
K\left(x_{i}, x\right)=\tanh \left(x_{i}(x+1)\right),
$$

where $x_{i}$ and $x$ are the training and test patterns, respectively, $\sigma$ is the global basis function width and $d$ is an input vector dimension.

Wu et al. (2012) studied the hybrid kernel function, which is a combination two kernel functions namely as linear kernel and local kernel function (RBF). The results of SVM models, which are created using hybrid kernel function, perform better than those created using ordinary functions.

\section{Review of SVM applications in structural engineering}

\subsection{Modeling the material properties of concrete using SVM}

Cement concrete is one of the most popular materials used in structural engineering. Modeling and predicting the concrete parameters has been a difficult task since the concrete contains several compounds namely as cement, sand, aggregate, water and admixtures and because of the nonlinearity between the relationships of these dependent and independent compounds. Support vector machines are one of the computational tools that attempt to solve these complex real life problems. The fallowing parts give detailed review of literature concerning the application of SVM in modeling the parameters of various types of concrete.

\subsubsection{Applications in modeling the strength of concrete}

Concrete strength is a substantial characteristic as it has a strong relationship with the quality and strength of overall structure. Several researchers implemented support vector machines approach in prediction of concrete strength successfully. Shengguo and Junbo (2007) used two types of kernel functions and found that the predictions of developed SVM model match fairly well with those of experiments. 
Xu et al. (2008) established a SVM-based mathematical model to investigate the relation between the strength and physical quantities that they obtained from nondestructive testing. They discovered that this method has advantages such as less computational time and high precision in predictions. This new method can be used for concrete strength conversion for nondestructive examinations.

High temperature causes serious damage in concrete structure. The nonlinearity of the relationship between material properties of concrete and fire exposure induces the difficulty of correct estimation of exposed temperature. Chen et al. (2009) produced a SVM model that is fairly feasible in predicting the exposed temperature values and they also underlined the importance of the numbers of effective parameters.

An example of strength prediction is provided by the study of Hai-xia (2010) who implemented support vector machines approach to predict the strength of high strength concrete. They compared the SVM results to those of actual experiments as well as regression, back-propagation (BP) network and radial basis function (RBF) network. They also emphasized the capability of SVM in prediction of concrete strength.

Prediction of elastic modulus is also a significant property as it is used to calculate deformation of structures. As an example of this, Yan and Shi (2010) proposed a SVM model in order to investigate the applicability of support vector machines in predicting elastic modulus of normal and high strength concrete. They also performed a comparison of SVM results and other proposed models as well as experimental outcomes. They concluded that the performance and generalization capability of SVM model are superior to those of other models.

Bin et al. (2011) produced a model to estimate the concrete compressive strength of two sets cubic samples one of which contains fly ash whereas the other contains fly ash with slag ash admixtures. It is stated that the model performed better prediction accuracy than the linear regression method and is more stable than the BP artificial neural network.

Integrated approaches are also effective when predicting concrete properties. An example of this is provided by the work of Gilan et al. (2011) who predicted the concrete compressive strength with support vector regression by adopting evolutionary fuzzy function. They compared the robustness and the generalization capability of evolutionary fuzzy function with support vector regression (EFF-SVR) model with some existing modeling approaches such as adaptive neural-fuzzy inference system (ANFIS), fuzzy function with least squared estimation (FF-LSE), artificial neural network and improved FF-LSE. The results indicated the better performance and capability of EFF-SVR model.

Modeling of reinforced and prestressed concrete deep beams is presented by Pal and Deswal (2011) who implemented SVM to predict the shear strength. For com- parison, they also applied a back-propagation neural network and three empirical equations for deep beams. The results revealed that the SVM model performs better and the parametric studies exhibit the importance of effective parameters such as concrete strength and ratio of shear span to effective depth of beam on strength prediction.

Wang et al. (2011) proposed a model based on SVM in order to forecast the concrete strength and feasibility. The results suggested that SVM is a better approach to express the relationship between concrete strength and effective factors.

Sriraam et al. (2012) employed the SVM for investigating the feasibility of using granite fines as a replacement for river-bad sand in concrete. Results indicated that the implementation of SVM induces high performance in predicting the concrete strength.

The use of robust models is required for estimating the compressive strength of no-slump concrete whose properties and constituents are reasonably sensitive. Sobhani et al. (2013) developed a SVM model to predict the compressive strength of no-slump concrete and compared results with optimized neural network (ANN) model. It is stated that although both models exhibited high accuracy in prediction and generalization capability, SVM was very rapid comparing to ANN models.

Sun et al. (2013) implemented least squares support vector machine (LS-SVM) for predicting the strengths of concrete specimens with high volume fly ash admixture. They stated that LS-SVM model could avoid the drawbacks of neural networks (ANN) namely as over-training and weak generalization capability.

The relationship between the tensile strength and the compressive strength is studied by Yan et al. (2013) who produced a SVM model using the experimental data available in literature. The results are compared to those from experimental studies and are found to be in a good agreement. The results are compared to outcomes of empirical design equations and various models. It is stated that the SVM has a strong potential for estimating the splitting tensile strength from compressive strength.

Another example for modeling the concrete strength is the study of Yang and Dong (2013), they employed SVM to investigate the feasibility of this approach. The results are compared to those of generalized regression neural network method.

Yuvaraj et al. (2013) developed a fracture mechanics based SVM model to estimate the features of high strength and ultra-high strength concrete beams. The model attempted to predict the values of fracture energy, critical stress intensity factor, critical crack tip opening displacement and failure loads. The results obtained from produced models were in a good agreement with those of the experimental values.

\subsubsection{Predicting the concrete corrosion}

Durability of structures is of great concern in structural engineering and is affected significantly by the corrosion 
of concrete and reinforcing steel. In this regard, predicting the corrosion severity becomes a substantial phenomenon for the researchers.

An example to prediction of corrosion severity is provided by Shujian et al. (2007) who implemented support vector machines as a classifier of corrosion severity. It is stated by the researchers that the method has advantage of high accuracy in classification.

Zhang and Song (2012) conducted a test of fly ash concrete specimens in sulfuric acid and modeled the results by means of support vector machines approach. Comparing the results with measured values, it is implied that this new method of computation has capability to predict the sulfuric acid corrosion of concrete.

The mechanical properties of corroded reinforced concrete are investigated by Yang et al. (2014) who conducted tests on specimens under repeated loads. Using support vector machines, the deflection and maximum crack width parameters are predicted and compared to those of test results. A high prediction accuracy of the model is observed.

\subsubsection{Applications in modeling self-compacting concrete (SCC) properties}

Self-compacting concrete (SCC) is a type of concrete that requires no mechanical compaction and is able to take the shape of the formwork without vibrators. This feature makes it popular as it reduces labor costs significantly and accelerates the construction progress. Following studies performs the estimation of SCC material properties.

Siddique (2008) investigated the potential of SVM approach in predicting the compressive strength and slump flow of self-compacting concrete. The results are compared with those of back propagation neural network model and it is observed that the SVM has a greater performance both for compressive strength and slump flow prediction.

A predictive model based on SVM is constructed by Cao et al. (2013) in order to predict the elastic modulus of self-compacting concrete. Through the analysis and comparison with test results, it is proved that this modeling technique is useful and powerful.

Another example of the prediction of SCC properties is the work of Aiyer et al. (2014) who examined the capability of least squares support vector machines (LS-SVM) for predicting the compressive strength of self-compacting concrete. The results indicated that the LS-SVM model performed better than ANN.

\subsubsection{SVM for structural reliability}

The uncertainties related to material characteristics and geometry conditions commonly exist in structural engineering. These uncertainties can impact the design performance significantly and result in serious complications. In this regard, structural reliability analyses are performed to detect the effect level.
$\mathrm{Li}$ and $\mathrm{Lu}$ (2007) proposed two SVM-based approaches for structural reliability analysis. The approximation of implicit performance function is provided by the implementation of SVM. Comparisons among the proposed reliability analysis and classical ones implied that the SVM method has capability both in performance function and failure probabilities.

\subsubsection{Applications in prediction of concrete carbonation}

Although it is not as much as corrosion, concrete carbonation is also a serious threat for structural durability. Thus, the estimation of carbonation level is of significant importance structural engineering practice.

As an example to this, Zhitao et al. (2008) employed SVM to forecast concrete carbonation level. The comparison of results with those of BP network suggested that SVM method could perform much better and could be a useful reference for application in different engineering disciplines.

The carbonation depth of prestressed concrete is investigated by Can (2009) who constructed a SVM model to perform the analysis. Two different kernel functions namely as wavelet kernel function and radial kernel function are used in SVM analysis. Xiang (2009) also studied the prediction of carbonation depth in concrete by means SVM. The results are compared to those from neural network modeling and it is observed that the SVM has higher accuracy and generalization capability.

\subsection{Damage identification}

Damage assessment has drawn a great attention from several engineering practitioners in recent years (Zhang et al. 2010a). SVM is a newly emerging method in damage identification and classification of the structures.

C.-C. Liu and J. Liu (2010) constructed a SVM based model for damage identification of a long-span arch bridge considering the variation ratio of curvature mode. The precision of the used model is verified by comparing the results with those from RBF neural network.

Another example of damage identification is the study of Tesfamariam and Liu (2010) who conducted eight different statistical damage classification methods one of which is support vector machines. It is observed that the performance of SVM model was one of the best among others.

Zhang et al. (2010a) stated, in their paper, that the performance of SVM in predicting the grouting quality of grouted beams is quite accurate in comparison to ANN's. They obtained the experimental results after nondestructive tests they conducted for grouting quality.

A SVM-based model for pattern identification of structural damage is presented by Zhang et al. (2010b) who performed the analyses by using wavelet kernel function of SVM. It is found that SVM model is able to overcome the problem of other traditional methods that are insensitive to natural frequencies and other dynamic parameters. 
Gao et al. (2012) utilized least squares support vector machines (LS-SVM) for damage diagnosis of concrete girder in order to determine damage degree and location. Kernel parameters are optimized to improve the generalization capability of the model. High identification precision by LS-SVM model is observed.

Another example of damage identification in concrete samples is provided by Xie et al. (2013) who employed the SVM approach to predict the location of voids based on ground penetrating radar (GPR) technique. The study showed that the SVM exhibits promising performance in the GPR identification of voids in concrete.

Zhu and Hao (2007) employed wavelet support vector machines for structural health monitoring. The response signals of a structure under impact load are collected and turned into wavelet packet components. Then, the energies of these components are calculated as feature vectors. SVM is utilized for training and classification based on these feature vectors. It is stated that the method can be used reliably for damage monitoring.

Zhang et al. (2006) showed the ability of support vector regression based approach for structural health monitoring of large-scale structures. According to authors, SVM can reduce the computation time and give accurate results. Also, an on-line SVR-based identification approach is presented to identify nonlinear structural parameters (Zhang, Sato 2006).

Satpal et al. (2013), in their study, investigated the effectiveness of SVM in health monitoring of beam-like structures. The results indicated the high performance of SVM without considering the health state of data used. Cheng and Hoang (2014c) utilized LS-SVM method for the purpose of risk score inference for bridge maintenance. The findings demonstrated that the method is successful also for decision-making purposes.

\subsection{Miscellaneous applications of SVM in structural engineering}

Yinfeng et al. (2008) proposed a SVM-based two-stage method to estimate and simulate the nonlinear dynamic response of structures. SVM is used during the second stage wherein the predicted linear responses and excitation is employed to approximate nonlinear mapping. The results demonstrated that the method can be used conveniently to predict the nonlinear structural response.

Samui and Kim (2012) developed SVM to identify the fracture parameters, critical stress intensity factor and the critical crack tip opening displacement of concrete. The results of the model are compared with ANN model and other empirical equations. It is concluded that SVM is a robust technique to predict fracture parameters of concrete.

In order to estimate the tangential displacement of a concrete dam, Ranković et al. (2014) presented a model based on support vector machines. The model is created using the data collected during fourteen years. The comparison of SVM results with experimental data confirmed the high performance capability of SVM approach.
Kromanis and Kripakaran (2014) investigated the structural performance monitoring of bridges that are subjected to thermal factors. They proposed a model based on SVM to predict the relationship between temperature distribution and structural response. The study confirmed the accuracy of this novel application. Also, SVM is applied to several other civil engineering disciplines successfully (Cheng, Hoang 2014a, b; Chou et al. 2013; Erdis 2013).

Additionally, other soft computing techniques such as ANFIS and ANN are also applied successfully to structural engineering problems (Amani, Moeini 2012; Cevik 2011; Cevik et al. 2012; Sonebi, Cevik 2009). The results of SVM and ANFIS models are found to be close and highly accurate noting that both modeling techniques have similar theoretical background.

\section{Case studies}

This paper also reports case studies in which we employed SVM in three different structural engineering problems and discussed the results. Emphasis was placed on verification of SVM performance by applying it to three unrelated problems wherein different structural members are experimented. The first example focuses on the punching shear strength of concrete slabs reinforced with fiber-reinforced polymer rebars. Secondly, ultimate load capacity of steel fiber reinforced concrete (SFRC) corbels is modeled by means of SVM. Final example gives insight into SVMbased modeling of reinforced concrete haunched beams.

\subsection{Punching strength of FRP-reinforced slabs}

In recent years, the use of fiber-reinforced polymer (FRP) in structures has drawn a great attention of engineers since it is a potential replacement of traditional steel and is free of corrosion problem. FRPs can be manufactured in different types such as rebar, plates and sheets. The stressstrain behavior of FRP rebars and traditional steel rebars are illustrated in Figure 2.

There exist several design models and empirical equations for predicting the punching shear capacity of FRP-reinforced two-way slabs as shown in Table 1 (El-Ghandour et al. 2003; Hassan et al. 2013; Hussein et al. 2004; Lee et al. 2009; Matthys, Taerwe 2000; Nguyen-Minh, Rovňák

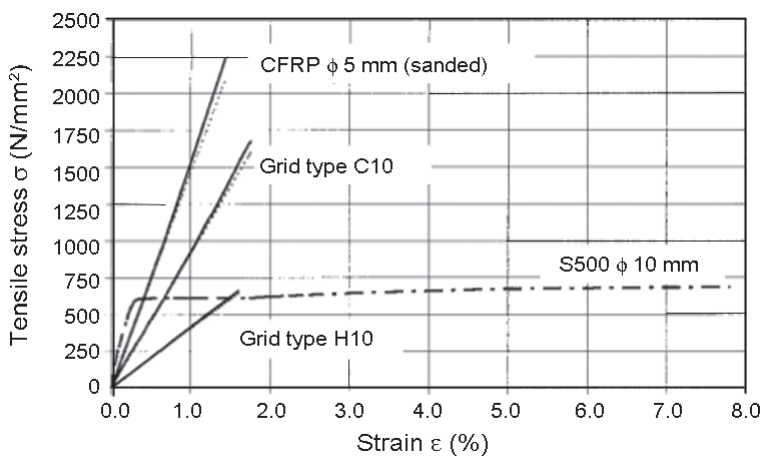

Fig. 2. Stress strain behavior of FRP bars (Matthys, Taerwe 2000) 
Table 1. Existing formulas for estimation of punching shear resistance of FRP reinforced two-way slabs

\begin{tabular}{|c|c|c|}
\hline Source & Formula & Remarks \\
\hline $\begin{array}{l}\text { ACI 318-11 (2011) } \\
\text { Eqn (8) }\end{array}$ & $P=0.33 \sqrt{f_{c}} b_{0,0.5 d} d$ & $b_{0,0.5 d}=4(c+d)$ \\
\hline $\begin{array}{l}\text { BS 8110-97 (1997) } \\
\text { Eqn (9) }\end{array}$ & $P=0.79(100 \rho)^{1 / 3}\left[\frac{400}{d}\right]^{1 / 4}\left[\frac{f_{c k}}{25}\right]^{1 / 3} b_{0,1.5 d} d$ & $\begin{array}{l}b_{0,1.5 d}=4(c+3 d) \\
f_{c k}=\text { cubic compressive } \\
\text { strength of concrete }\end{array}$ \\
\hline $\begin{array}{l}\text { El-Ghandour et al. } \\
\text { (2003) (ACI) } \\
\text { Eqn (10) }\end{array}$ & $P=0.33 \sqrt{f_{c}}\left[\frac{E_{f}}{E_{s}}\right]^{1 / 3} b_{0,0.5 d} d$ & $\begin{array}{l}b_{0,0.5 d}=4(c+d) \\
E_{s}=210 G P a\end{array}$ \\
\hline $\begin{array}{l}\text { El-Ghandour et al. } \\
\text { (2003) (BS) } \\
\text { Eqn (11) }\end{array}$ & $P=0.79\left[100 \rho(1.8) \frac{E_{f}}{E_{s}}\right]^{1 / 3}\left[\frac{400}{d}\right]^{1 / 4}\left[\frac{f_{c k}}{25}\right]^{1 / 3} b_{0,1.5 d} d$ & $\begin{array}{l}b_{0,1.5 d}=4(c+3 d) \\
E_{s}=210 G P a\end{array}$ \\
\hline $\begin{array}{l}\text { Matthys and } \\
\text { Taerwe (2000) } \\
\text { Eqn (12) }\end{array}$ & $P=1.36 \frac{\left[100 \rho \frac{E_{f}}{E_{S}} f_{c m}\right]^{1 / 3}}{d^{1 / 4}} b_{0,1.5 d} d$ & $\begin{array}{l}f_{c m}=\text { mean concrete compressive } \\
\text { strength of cylinder specimens } \\
\text { at } 28 \text { days }\end{array}$ \\
\hline $\begin{array}{l}\text { Ospina et al. (2003) } \\
\text { Eqn (13) }\end{array}$ & $P=2.77\left(\rho f_{c}\right)^{1 / 3}\left[\frac{E_{f}}{E_{s}}\right]^{1 / 2} b_{0,1.5 d} d$ & $\begin{array}{l}b_{0,1.5 d}=4(c+3 d) \\
E_{s}=210 G P a\end{array}$ \\
\hline $\begin{array}{l}\text { Zaghloul (2003) } \\
\text { Eqn (14) }\end{array}$ & $P=0.07\left(\rho f_{c} E_{f}\right)^{1 / 3} b_{0,0.5 d} d$ & $b_{0,0.5 d}=4(c+d)$ \\
\hline $\begin{array}{l}\text { El-Gamal et al. } \\
(2005) \\
\text { Eqn (15) }\end{array}$ & $P=0.33 \sqrt{f_{c}}(1.2)^{N} b_{0,0.5 d} d \alpha$ & $\begin{array}{l}b_{0,0.5 d}=4(c+d) \\
\alpha=0.62\left(\rho E_{f}\right)^{1 / 3}\left[1+\frac{8 d}{b_{0,0.5 d}}\right]\end{array}$ \\
\hline $\begin{array}{l}\text { Theodorakopoulos } \\
\text { and Swamy (2007) } \\
\text { Eqn (16) }\end{array}$ & $\begin{array}{l}P=\frac{1}{2} 0.234 f_{c u}^{2 / 3}\left[\frac{100}{d}\right]^{1 / 6}\left[\frac{2 \alpha_{f} \lambda_{f}}{1+\alpha_{f} \lambda_{f}}\right] b_{0,1.5 d} d \quad \text { for } \\
\alpha_{f}>0.33 \\
\alpha_{f}=\rho_{f} E_{f}\left[\frac{0.0105}{0.145 f_{c u}}\right] \quad \text { with } f_{c u}=f_{c} / 0.8 \\
\lambda_{f}=\left(k_{f} / 6\right)\left(-1+\sqrt{1+48 / \alpha_{f}}<1 \text { with } k_{f}=0.55\right.\end{array}$ & $\begin{array}{l}b_{0,1.5 d}=4(c+3 d) \\
E_{s}=210 G P a \\
f_{c u}=\text { ultimate compressive } \\
\text { strength of concrete. }\end{array}$ \\
\hline
\end{tabular}

2012; Ospina et al. 2003; Zaghloul 2003; Zhang 2006). All of these researchers tested slabs with FRP reinforcing bars or two-dimensional grids. All of the slabs had unrestrained edges and were subjected to a central column load. Carbon (CFRP), glass (GFRP) or a hybrid of carbon and glass (HFRP) types of fibres were used.

In this part of the study, we utilized SVM to estimate the ultimate punching shear load of FRP-reinforced twoway slabs. The main focus is to propose a new model for predicting the punching shear strength of FRP reinforced two-way slabs. The SVM approach is applied to the tests of a concrete member reinforced with composite fibers for the first time in the literature. Thus, an extensive literature review has been conducted on FRP reinforced two-way slabs. Experimental database that is utilized for performing the support vector machine analysis are given in Appendix (Table A.1). The model includes the input variables of column section $(c)$, effective flexural depth of slab $(d)$, elastic modulus of FRP $\left(E_{f}\right)$, reinforcement ratio ( $\rho)$, compressive strength of concrete $\left(f_{c}\right)$ and the target variable as ultimate punching load $(P)$. 


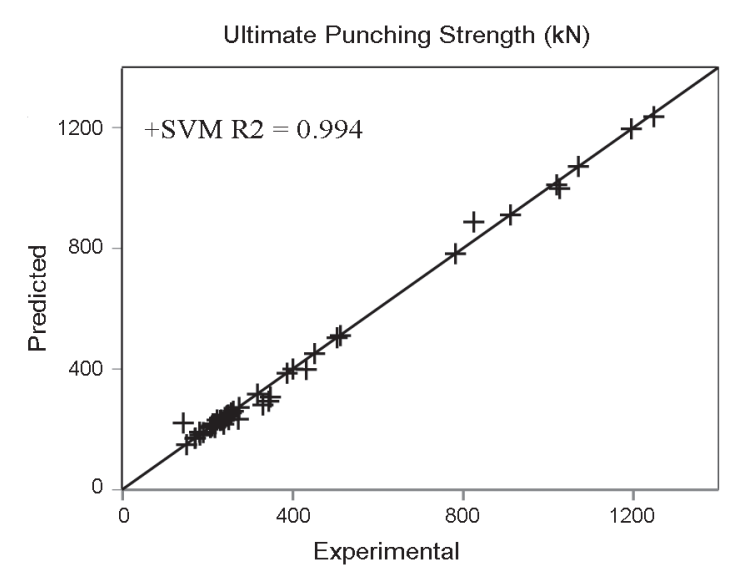

Fig. 3. Performance of proposed SVM model vs. test results

A process of model creation ( 8 models) has been performed by using 2 different SVM types (Nu-SVR and Epsilon-SVR) and 4 different SVM kernel functions (Linear, Polynomial, Radial basis function, Sigmoid). $80 \%$ of the database is used as training set and the remaining $20 \%$ is used for validation in all models. The radial basis function (RBF) model is selected for comparison and parametric study as it exhibited the best performance among others.

According to obtained statistical values, SVM model has the lowest mean squared error (MSE) value of 485.2 whereas the closest MSE is that of Theodorakopoulos and Swamy (2007) with 2260.9. Additionally, SVM model exhibits the highest correlation coefficient $\left(R^{2}\right)$ of 0.994 . Test results versus predicted results of SVM model is illustrated in Figure 3. Furthermore, an evaluation process has been performed to test the accuracy of proposed model by means of numerical results of the same experimental database and empirical equations available in the literature. The accuracy of proposed model is found to be higher than numerical results and existing analytical equations and design codes available in the literature.

A parametric study is performed to test the generalization capability of SVM model. For this, a new dataset has been generated for each variable and the ranges of those variables were kept more or less in between the minimum and maximum of variables in experimental dataset. By implementing the generated data to SVM model, main effect (Fig. 4) and interaction plots (Fig. 5) of each variable are obtained. The main effect plot is a significant tool to display the effect of each variable on punching shear capacity. This graphical tool allows viewing the overall importance of variable effects on the output and provides a general snapshot. On the other hand, the interaction plot is an essential tool to observe the effect of each input parameter in conjunction with other inputs. This tool allows viewing the effect of each variable in detail. The same parametric dataset, which is used for main effect plot, has been utilized in order to obtain interaction plot provided in Figure 5.

Main effect (Fig. 4) and interaction plot (Fig. 5) indicate that punching shear capacity of FRP-reinforced

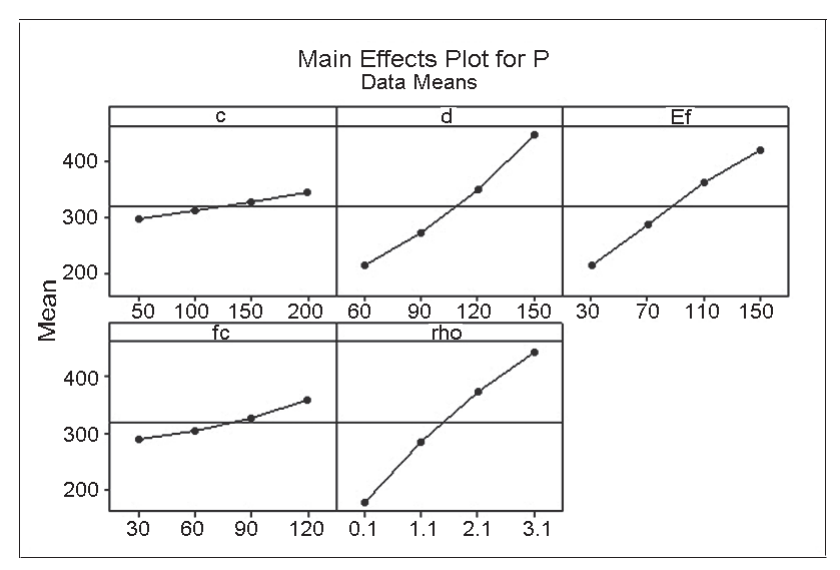

Fig. 4. Main effect trends for the parametric study on punching shear capacity

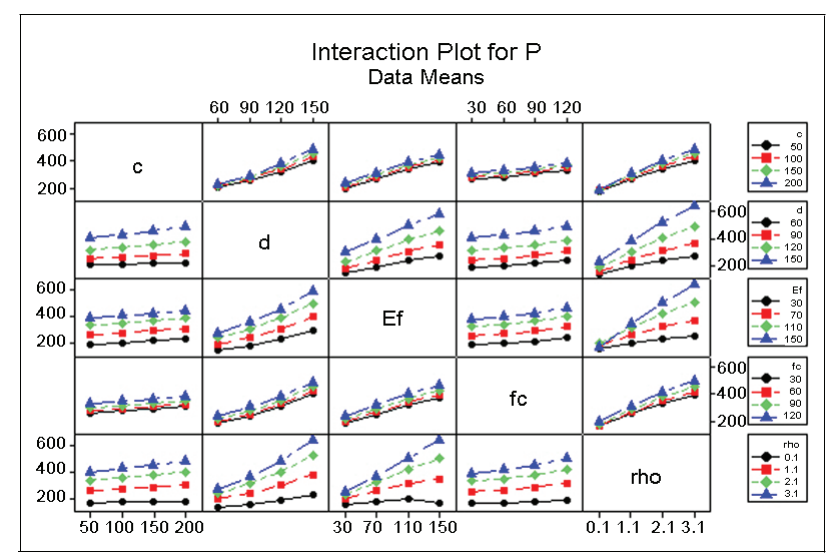

Fig. 5. Interaction effect plot of variables on punching shear capacity

two-way slabs is influenced significantly by all input parameters. In particular, $c$ (column section), $d$ (effective flexural depth of slab), $E_{f}$ (elastic modulus of FRP), $f_{c}$ (compressive strength of concrete) and $\rho$ (reinforcement ratio) have an increasing effect on punching shear load.

\subsection{Ultimate load capacity of Steel Fiber Reinforced Concrete (SFRC) corbels}

In the second case study, emphasis was placed on the prediction of ultimate load capacity of SFRC corbels. Corbels are structural elements primarily used in reinforced concrete and precast structures. The main function of corbels is to transfer vertical and horizontal loads to the members to which they are connected. Corbels can be the overhanging portion of beam with a small span length. Shear span to effective depth ratio $(a / d)$ of corbels is less than unity (Ersoy et al. 2010).

Use of steel fiber in reinforced concrete corbels provides considerable advantages. Previous studies related with corbels have concluded that reinforced concrete corbels which include only steel fibers as secondary reinforcement have almost the same load carrying capacity with those of horizontal stirrups are used against shear failure. 
Use of steel fiber facilitates the fabrication of corbels because of easier placement of it as compared to placement of horizontal stirrups. Steel fibers allow corbels to experience large deflections after achieving ultimate load without a dramatic loss in load carrying capacity or demonstrating a sudden and brittle failure (Fattuhi, Hughes 1989b).

The aim of this study is to present SVM for the prediction and analyses of ultimate load capacity of SFRC corbels for the first time in literature. The outcomes of the study will enable to understand and model the effects of various material and geometry parameters on the ultimate load capacity of SFRC corbels, which has not been studied so far.

\section{Previous experimental studies on SFRC corbels}

Fattuhi and Hughes studied a series of experiments on steel fiber reinforced corbels (Fattuhi 1987, 1990a, b, 1994b; Fattuhi, Hughes 1989a, b; Hughes, Fattuhi 1989). Fattuhi and Hughes investigated effects of steel fiber on load carrying capacity of corbels whose test configuration is shown in Figure 6. They changed various parameters (tensile and compressive strength of concrete, volume fraction of steel fiber, shear span, fiber aspect ratio, effective depth, reinforcement ratio) and observed the mechanical response of SFRC corbels.

Campione, Mendola and Mangiavillano studied the flexural behavior of fibrous reinforced corbels experimentally and suggested simple analytical expressions for bearing capacity by considering the shear contribution due to steel reinforcements and fibers (Campione et al. 2007).

Fattuhi (1994a) also investigated the mechanical behavior of trapezoidal SFRC corbels. High strength steel fiber reinforced corbels in trapezoidal form were experimented by Muhammad (1998) under monotonic and cyclic loading.

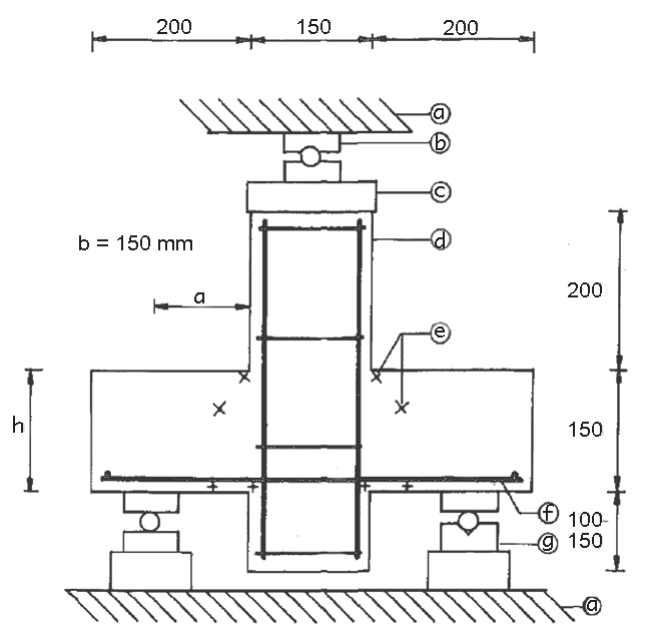

Test Arrangement: (a) Testing Machine; (b) Spherical Seat; (c) Loading Plate; (d) Concrete Specimen; (e) Demec Discs; (f) Main Bars; (g) Roller Support

Fig. 6. Test configuration of corbels experimented by Fattuhi and Hughes (Fattuhi 1990b)
In order to obtain an empirical equation for the prediction of the ultimate load capacity of SFRC corbels tested, Fattuhi proposed the following equation (Fattuhi 1990b):

$V_{n}=57.292 b h\left(f_{c t}\right)^{0.315}\left[\frac{a}{h}\right]^{-0.812}\left[\frac{f_{y}}{f_{c u}}\right]^{-0.049}\left[\frac{d}{h}\right]^{0.678} \rho^{C}$,

where $V_{n}$ is the nominal strength of a corbel, $f_{c t}$ is the tensile strength of concrete, a is the shear span ( $\mathrm{mm}), h$ is the overall depth $(\mathrm{mm}), f_{y}$ is yield strength of main reinforcement and fcu is the cubic compressive strength of SFRC, $d$ is the effective depth $(\mathrm{mm})$ and $\rho$ is the reinforcement ratio $(\%)$.

In this part of the study, the main focus is to compare the experimental results of SFRC corbels with the results of newly proposed SVM model. The SVM approach is applied to the experimental results of SFRC corbels for the first time in the literature. An experimental database on SFRC corbels has been gathered from the literature that is utilized for performing the support vector machine modeling (Table A.2). The proposed SVM model includes the input variables of cylindrical compressive strength of concrete $\left(f_{c}\right)$, shear span $(a)$, tensile strength of concrete $\left(f_{t}\right)$, overall depth $(h)$, steel-concrete strength ratio $\left(f_{y} / f_{c u}\right)$, effective depth $(d)$ and reinforcement ratio $(\rho)$. Yet, only most effective parameters are taken when performing the parametric study.

2 different SVR types (Nu-SVR and Epsilon-SVR) and 4 different SVR kernel functions (Linear, Polynomial, Radial basis function and Sigmoid) are utilized to create SVM models. $80 \%$ of the database is used as training set and the remaining $20 \%$ is used for validation in all models. The model whose performance is the best among others is selected for comparison and parametric study.

Additionally, an evaluation process has been performed to test the accuracy of proposed model by means of numerical results of the same experimental database and an empirical equation (Eqn (7)) proposed by Fattuhi (1990b). The comparison of SVM and empirical equation results compared experimental results are shown in Table A.2. According to obtained statistical values, SVM model has the lowest root mean squared error (RMSE) value of 4.735. Additionally, SVM model exhibits the highest goodness of fit $\left(R^{2}\right)$ by 0.975 . Test results versus predicted results of SVM model are illustrated in Figure 7. The accuracy of proposed model is found to be very high and in good agreement with test results.

Main effect (Fig. 8) and interaction plot (Fig. 9) indicate that ultimate shear load capacity of SFRC corbels is influenced by four input parameters namely as compressive strength of concrete $\left(f_{c}\right)$, reinforcement ratio $(\rho)$, fiber density $\left(v_{f}\right)$ and shear span-to-effective depth ratio $(a / d)$. The other parameters are not involved in modeling because of their low contribution. In particular, compressive strength of concrete $\left(f_{c}\right)$, reinforcement ratio $(\rho)$ and 


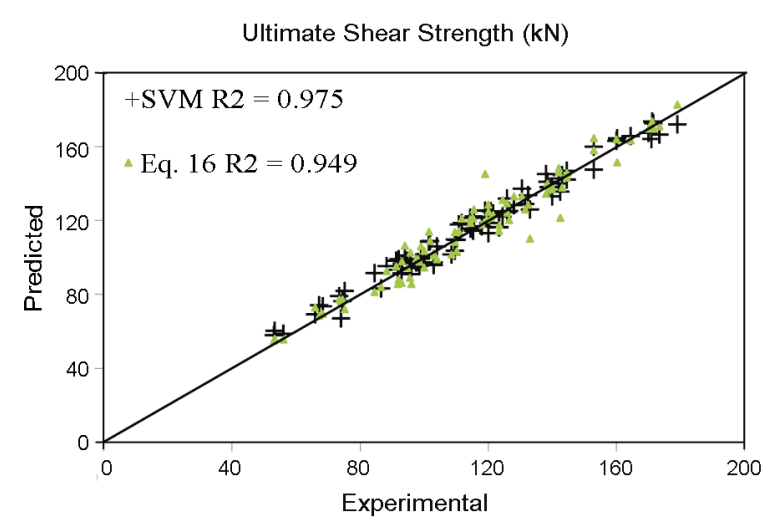

Fig. 7. Experimented versus predicted shear strengths (in KN)

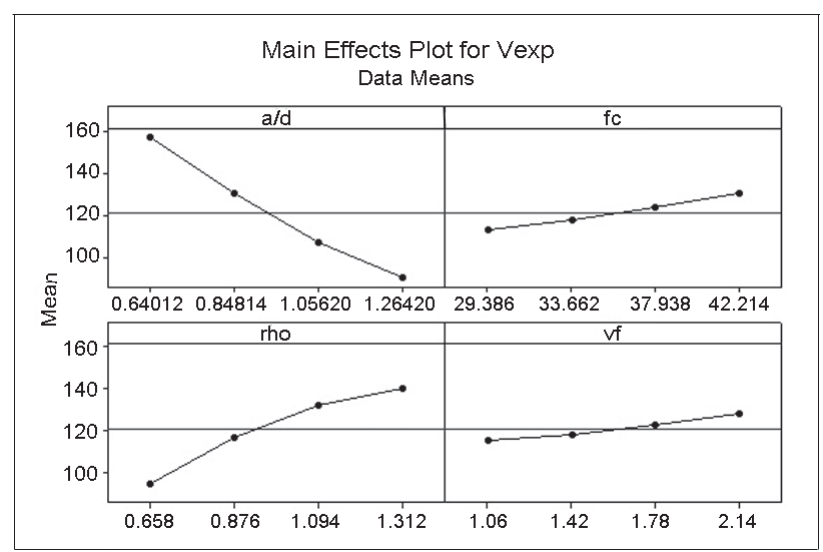

Fig. 8. Main effect trends for the parametric study on ultimate shear force of SFRC corbels

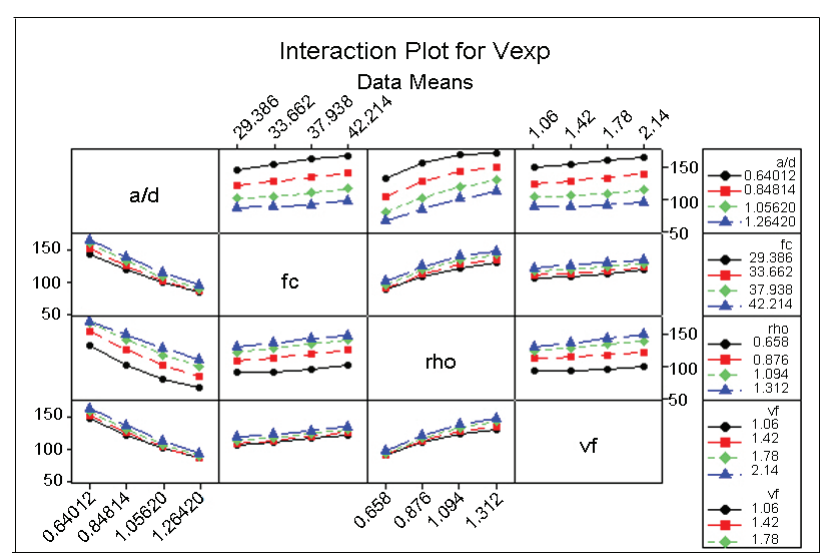

Fig. 9. Interaction effect plot of variables on ultimate shear capacity

fiber density $\left(v_{f}\right)$ have increasing effects on ultimate load whereas the increase in shear span-to-effective depth ratio (a/d) leads to lower load capacity.

It is found that the proposed SVM has generalization capability for the range of variables in experimental dataset. It can be observed from the interaction plots (Fig. 9) that the shear span-to-effective depth ratio (a/d) has a significant inversely proportional effect on ultimate load and this effect is pronounced more together with the influence of compressive strength $\left(f_{c}\right)$. Although the contribution of fiber density $\left.\left(v_{f}\right)\right)$ is rather low in comparison with other inputs, the increase rate in fiber density is pronounced more with the contribution of shear spanto-effective depth ratio $(a / d)$ and reinforcement ratio $(\rho)$.

It can be extracted from the parametric study of SFRC corbels that the results of SVM analysis are reliable and can be used in design and analysis process. Because the outputs of main effects plot and interaction plot are consistent with the outputs of experimental and analysis. For instance, the most important parameters influencing the ultimate load capacity of SFRC corbels are span-toeffective- depth ratio $(a / d)$ and reinforcement ratio $(\rho)$ and effect of steel fiber volume ratio is small when compared to these two parameters according to experiments carried by Fattuhi and Hughes. The similar situation exists according to the main effect and interaction effect graphs of SVM analysis.

\subsection{Shear capacity of reinforced concrete haunched beams}

The third case study focuses on the shear capacity prediction of $\mathrm{RC}$ haunched beams. Although reinforced concrete $(\mathrm{RC})$ haunched beams are widely used as bridges or portal frames and precast roof girders, there is a lack of studies in the literature investigating this topic (Nilson et al. 2011). Scarce in experimental studies is the main impediment to include this topic in details by international building practice codes. As a result of various experimental studies, it can be concluded that the behavior and failure of the RC haunched beams differs as compared to prismatic section RC beams. Figure 10 illustrates the haunched beams experimented by Debaiky and Elniema (1982), Stefanou (1983), Tena-Colunga et al. (2008) and Nghiep (2011).

In this part of the study, SVM approach is implemented to estimate the shear capacity of RC haunched beams. For this, experimental data is collected and used for modeling by means of SVM. The material parameters that are taken to investigate the behavior of the RC haunched beams are shear span-to-critical effective depth ratio $\left(a / d_{c r}\right)$, haunch slope $(\tan a)$, flexural reinforcement ratio $\left(\rho_{s}\right)$ and compressive strength of concrete $\left(f_{c}\right)$. Characteristics of tested beams and comparison of results are summarized in Table A.3. Figure 11 illustrates the test results versus predicted results of SVM model produced to predict the ultimate shear load of RC haunched beams.

Main effect (Fig. 12) and interaction plot (Fig. 13) show that ultimate shear capacity of reinforced concrete haunched beams is highly influenced by four particular input parameters namely as shear span-to-critical effective depth ratio $\left(a / d_{c r}\right)$, haunch slope (tana), reinforcement ratio $\left(\rho_{s}\right)$ and compressive strength of concrete $\left(f_{c}\right)$. The other parameters are ignored in modeling because of their low contribution. In particular, reinforcement ratio $(\rho)$, compressive strength of concrete $\left(f_{c}\right)$ and haunch slope 


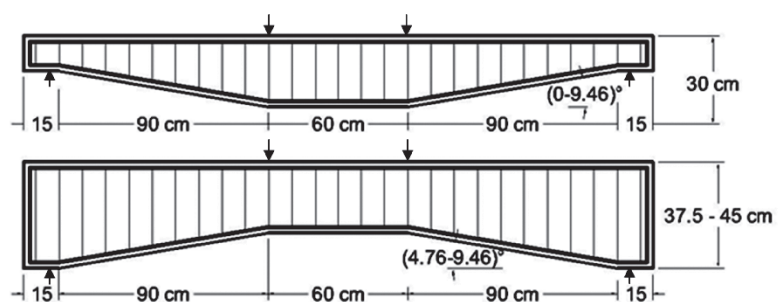

(a)

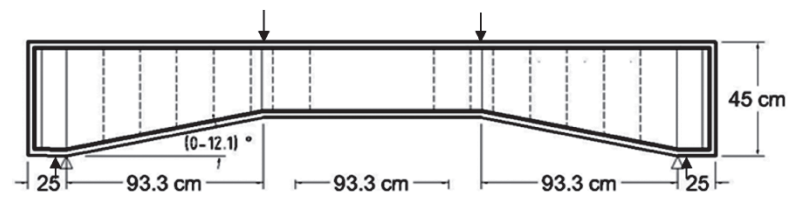

(c)
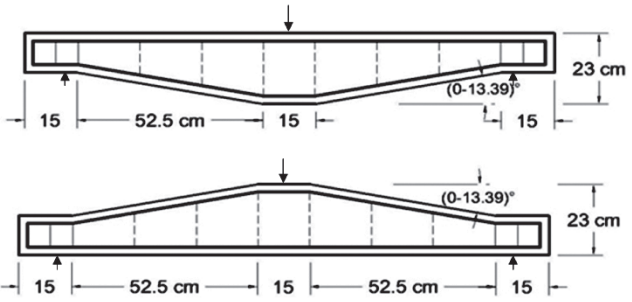

(b)

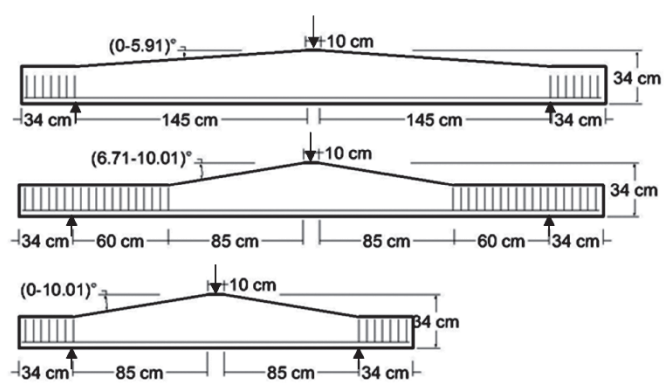

(d)

Fig. 10. Haunched beams tested by: (a) Debaiky and Elniema (1982); (b) Stefanou (1983); (c) Tena-Colunga et al. (2008); (d) Nghiep (2011)

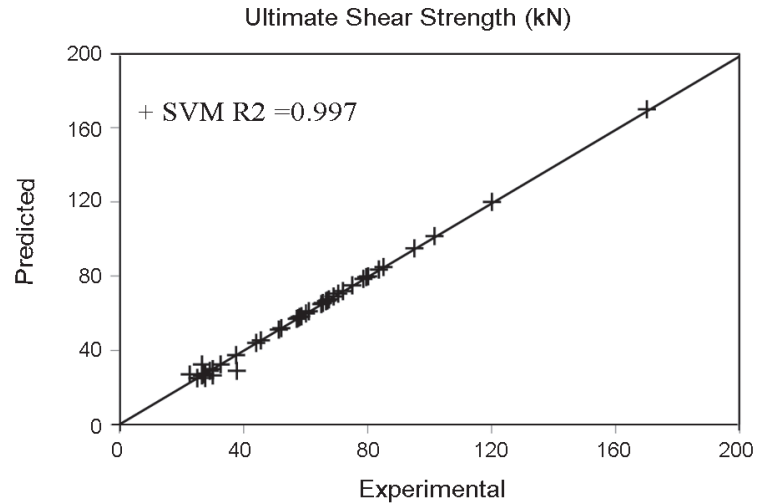

Fig. 11. Experimented versus predicted shear strengths (in $\mathrm{KN}$ )

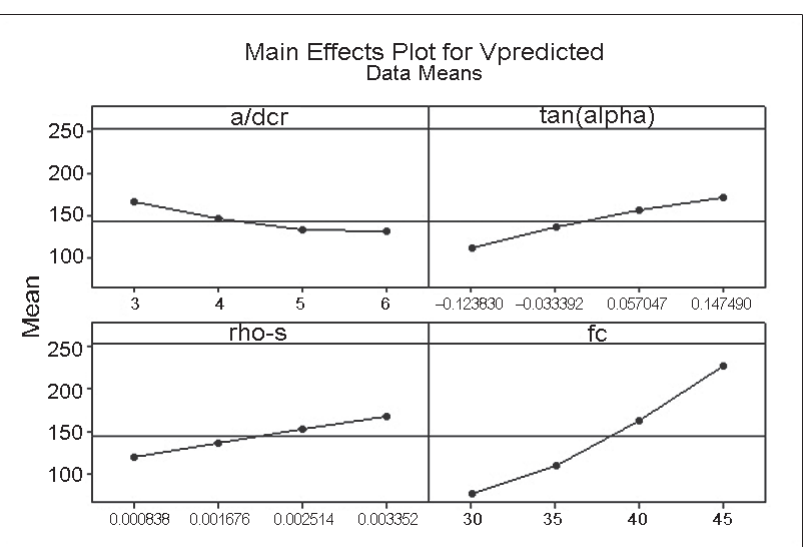

Fig. 12. Main effect trends for the parametric study on ultimate shear force of RC haunched beams

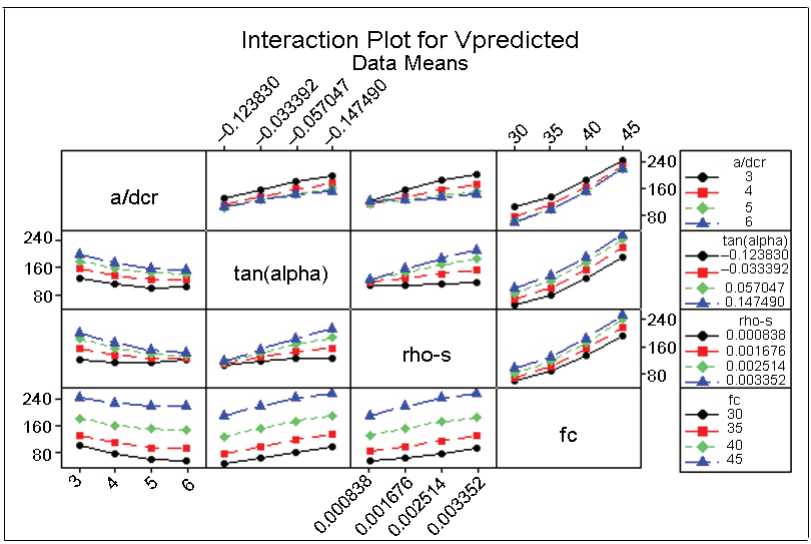

Fig. 13. Interaction plots for the parametric study on ultimate shear force of RC haunched beams

(tana) have increasing effects on ultimate load whereas the increase in shear span-to-critical effective depth ratio $\left(a / d_{c r}\right)$ leads to lower shear load capacity.

Figures 12 and 13 indicate that the proposed SVM has generalization capability for the range of variables in experimental dataset of haunched beams. The shear spanto-critical effective depth ratio $\left(a / d_{c r}\right)$ has an inversely proportional effect on ultimate load and this effect is pronounced more together with the influence of compressive strength $\left(f_{c}\right)$. The effect of compressive strength $\left(f_{c}\right)$ on ultimate load capacity is larger than remaining three parameters. Although the contributions of reinforcement ratio $\left(\rho_{s}\right)$ and haunch slope (tana) are rather low, their effects become significant with the contribution of concrete compressive strength $\left(f_{c}\right)$. 


\section{Advantages of support vector machines}

Advantages of support vector machines are as follows:

- The problems of outliers and noise can be minimized by proper setting of C-parameter (Vapnik 2000).

- Regardless of data distribution (whether it is nonmonoton or non-linearly seperable), SVMs can exhibit high performance for classification problems and give accurate results (Cristianini, Shawe-Taylor 2000).

- Noisy conditions can be dealt with by automatic identification and incorporation of support vectors as the model minimizes the effect of non-support vectors while training (Han et al. 2007).

- Thanks to some key training vectors in the models, future predictions can be improved by tracing back in the historical modeling events (Han et al. 2007; Mukherjee, Vapnik 1999).

\section{Disadvantages of support vector machines}

Disadvantages of support vector machines are as follows: - The main problem of SVMs is the process of selecting the suitable kernel function and hyper parameters as it based on trial and error process, which is timeconsuming (Ccoicca 2013; Yu et al. 2006).

- Interpretation and understanding of nonlinear SVR model behavior can be quite difficult because of the fact that the mapping of nonlinear inputs into high dimensional feature space involves high complexity. Thereby, the training process takes more time comparing to those of linear models (Raghavendra, Deka 2014; Tripathi et al. 2006).

- Probabilistic forecasting may not be performed since SVMs aim for point predictions (Raghavendra, Deka 2014).

- Since the model is dependent on past data records, model extrapolation performance may be unsatisfactory incase the past data are inconsistent (Raghavendra, Deka 2014).

\section{Conclusions}

In this study, the key principles of support vector machines (SVM) and its applications in structural engineering have been reviewed. Additionally, its applicability has been proved by providing three case studies namely as punching shear capacity of FRP-reinforced two-way slabs, ultimate shear capacity of SFRC corbels and the load capacity of haunched beams.

The first case study has been conducted using 47 experimental records of the punching shear capacity of FRPreinforced two-way slabs. The SVM is found to be robust, highly accurate and capable to generalize for predicting the punching shear capacity. $\left(R^{2}=0.994\right)$ The second example is performed using 84 experimental data on shear capacity of SFRC corbels. This example also confirmed the robustness and accuracy as well as generalization capability of SVM approach with a correlation coefficient of $R^{2}=0.975$. In this example, the results are also compared to those of an empirical equation provided in the literature. The third example focuses on the shear capacity of reinforced concrete haunched beams. SVM is applied to predict the ultimate shear capacity using 47 experimental records. Also, the prediction performance of SVM is found to be high $\left(R^{2}=0.997\right)$ and the generalization capability is confirmed.

Based on the above-mentioned results, fallowing conclusions can be drawn:

- Support vector machines approach has successfully been implemented by several researchers focusing on structural engineering problems.

- SVM approach is a highly effective machine learning method that can be applied to structural engineering problems.

- SVM technique is superior to several other methods considering the high generalization capability performance.

- SVM can safely be implemented to wide range of structural problems even though the problems are highly unrelated.

- As the performance of SVM models are largely dependent on the type of kernel function, it is required to select the suitable kernel function in order to get satisfactory results.

- Encouraging performance of SVM method can draw attention of researchers and engineers who desire to find out the impact rate of inputs on an output of a structural engineering problem.

\section{References}

Aiyer, B. G.; Kim, D.; Karingattikkal, N.; Samui, P.; Rao, P. R. 2014. Prediction of compressive strength of self-compacting concrete using least square support vector machine and relevance vector machine, KSCE Journal of Civil Engineering 18(6): 1753-1758.

http://dx.doi.org/10.1007/s12205-014-0524-0

ACI 318-11 Building code requirements for structural concrete and commentary. Americal Concrete Institute, USA, 2011. $373 \mathrm{p}$.

Amani, J.; Moeini, R. 2012. Prediction of shear strength of reinforced concrete beams using adaptive neuro-fuzzy inference system and artificial neural network, Scientia Iranica 19: 242-248. http://dx.doi.org/10.1016/j.scient.2012.02.009

Bin, C.; Xuemang, G.; Guohua, L. 2011. Prediction of concrete properties based on rough sets and support vector machine method, Journal of Hydroelectric Engineering 30(6): 251257.

Boser, B. E.; Guyon, I.; Vapnik, V. 1992. A training algorithm for optimal margin classifiers, in Proc. of the Fifth Annual Workshop on Computational Learning Theory, 1992, Pittsburgh. ACM Press, 144-152.

BS 8110-97 Flexural and shear beam design. British Standards Institution, UK, 1997. 168 p.

Campione, G.; La Mendola, L.; Mangiavillano, M. L. 2007. Steel fiber-reinforced concrete corbels: experimental behavior and shear strength prediction, ACI Structural Journal 104(5): 570-579.

Can, H. 2009. Study on carbonation depth prediction of prestressed concrete based on wavelet SVM, Industrial Construction, 2009-S1. 
Cao, Y. F.; Wu, W.; Zhang, H. L.; Pan, J. M. 2013. Prediction of the elastic modulus of self-compacting concrete based on SVM, Applied Mechanics and Materials 357-360: 1023-1026. http://dx.doi.org/10.4028/www.scientific.net/ AMM.357-360.1023

Ccoicca, Y. J. 2013. Applications of support vector machines in the exploratory phase of petroleum and natural gas: a survey, International Journal of Engineering \& Technology 2(2): 113-125. http://dx.doi.org/10.14419/ijet.v2i2.834

Cevik, A. 2011. Neuro-fuzzy modeling of rotation capacity of wide flange beams, Expert Systems with Applications 38(5): 5650-5661. http://dx.doi.org/10.1016/j.eswa.2010.10.070

Cevik, A.; Arslan, M. H.; Saracoglu, R. 2012. Neuro-fuzzy modeling of torsional strength of $\mathrm{RC}$ beams, Computers and Concrete 9(6): 469-486.

http://dx.doi.org/10.12989/cac.2012.9.6.469

Chen, N.; Lu, W.; Yang, J.; Li, G. 2004. Support vector machine in chemistry. UK: World Scientific Publishing Co. 344 p.

Chen, B.; Chang, T.; Shih, J.; Wang, J. 2009. Estimation of exposed temperature for fire-damaged concrete using support vector machine, Computational Materials Science 44(3): 913-920.

http://dx.doi.org/10.1016/j.commatsci.2008.06.017

Cheng, M.-Y.; Hoang, N.-D. 2014a. Groutability prediction of microfine cement based soil improvement using evolutionary LS-SVM inference model, Journal of Civil Engineering and Management, 1-10. Article in Press.

Cheng, M.-Y.; Hoang, N.-D. 2014b. Interval estimation of construction cost at completion using least squares support vector machine, Journal of Civil Engineering and Management 20(2): 223-236.

http://dx.doi.org/10.3846/13923730.2013.801891

Cheng, M.-Y.; Hoang, N.-D. 2014c. Risk score inference for bridge maintenance project using evolutionary fuzzy least squares support vector machine, Journal of Computing in Civil Engineering 28(3), 04014003.

http://dx.doi.org/10.1061/(ASCE)CP.1943-5487.0000275

Cherkassky, V.; Ma, Y. 2002. Selection of meta-parameters for support vector regression, Artificial Neural Networks ICANN 2002, Lecture Notes in Computer Science 2415: 687-693. http://dx.doi.org/10.1007/3-540-46084-5 112

Chou, J.-S.; Tsai, C.-F.; Lu, Y.-H. 2013. Project dispute prediction by hybrid machine learning techniques, Journal of Civil Engineering and Management 19(4): 505-517. http://dx.doi.org/10.3846/13923730.2013.768544

Cortes, C.; Vapnik, V. 1995. Support-vector network, Machine Learning 20: 273-297. http://dx.doi.org/10.1007/BF00994018

Cristianini, N.; Shawe-Taylor, J. 2000. An introduction to support vector machines and other kernel-based learning methods. Cambridge: Cambridge University Press. 198 p. http://dx.doi.org/10.1017/CBO9780511801389

Debaiky, S. Y.; Elniema, E. I. 1982. Behavior and strength of reinforced concrete haunched beams in shear, ACI Journal Proceedings 79(3): 184-194.

El-Gamal, S.; El-Salakawy, E. F.; Benmokrane, B. 2005. A new punching shear equation for two-way concrete slabs reinforced with FRP bars, ACI Special Publication 230: 877-894.

El-Ghandour, A. W.; Pilakoutas, K.; Waldron, P. 2003. Punching shear behavior of fiber reinforced polymers reinforced concrete flat slabs: experimental study, Journal of Composites for Construction 7(3): 258-265. http://dx.doi.org/10.1061/(ASCE)1090-0268(2003)7:3(258)

Erdis, E. 2013. The effect of current public procurement law on duration and cost of construction projects in Turkey, Journal of Civil Engineering and Management 19(1): 121-135. http://dx.doi.org/10.3846/13923730.2012.746238
Ersoy, U.; Özcebe, G.; Tankut, T. 2010. Reinforced concrete. Odtü Gelistirme Vakfi Yayincilik. 660 p.

Fattuhi, N. I. 1987. SFRC corbel tests, ACI Structural Journal 84(2): 119-123.

Fattuhi, N. 1990a. Column-load effect on reinforced concrete corbels, Journal of Structural Engineering 116(1): 188-197. http://dx.doi.org/10.1061/(ASCE)07339445(1990)116:1(188)

Fattuhi, N. 1990b. Strength of SFRC corbels subjected to vertical load, Journal of Structural Engineering 116(3): 701-718. http://dx.doi.org/10.1061/(ASCE)07339445(1990)116:3(701)

Fattuhi, N. I. 1994a. Reinforced corbels made with plain and fibrous concretes, ACI Structural Journal 91(5): 530-536.

Fattuhi, N. I. 1994b. Strength of FRC corbels in flexure, Journal of Structural Engineering 120(2): 360-377. http://dx.doi. org/10.1061/(ASCE)0733-9445(1994)120:2(360)

Fattuhi, N. I.; Hughes, B. P. 1989a. Ductility of reinforced concrete corbels containing either steel fibers or stirrups, $A C I$ Structural Journal 86(6): 644-651.

Fattuhi, N. I.; Hughes, B. P. 1989b. Reinforced steel fiber concrete corbels with various shear span-to-depth ratios, $A C I$ Materials Journal 86(6): 590-596.

Gao, P.-P.; Wang, J.; Li, X.-M. 2012. Damage diagnosis model for concrete girder based on LS-SVM optimized by HPSO, Journal of Water Resources and Architectural Engineering 3: 036.

Gilan, S.; MashhadiAli, A.; Ramezanianpour, A. 2011. Evolutionary fuzzy function with support vector regression for the prediction of concrete compressive strength, in Fifth UKSim European Symposium on Computer Modeling and Simulation (EMS), November 2011, IEEE, 263-268.

Hai-xia, C. 2010. Strength prediction of high strength concrete using SVM and its application, Concrete 5, 018.

Han, D.; Chan, L.; Zhu, N. 2007. Flood forecasting using support vector machines, Journal of Hydroinformatics 9(4): 267-276. http://dx.doi.org/10.2166/hydro.2007.027

Hassan, M.; Ahmed, E.; Benmokrane, B. 2013. Punching-shear strength of normal and high-strength two-way concrete slabs reinforced with GFRP bars, Journal of Composites for Construction 17(6), 04013003.

http://dx.doi.org/10.1061/(ASCE)CC.1943-5614.0000424

Hsu, C.-W.; Chang, C.-C.; LIN, C.-J. 2003. A practical guide to support vector classification [online], [cited 10 Sep 2014]. Department of Computer Science, National Taiwan University, Taiwan. Available from Internet:

http://www.csie.ntu.edu.tw/ cjlin/papers/guide/guide.pdf.

Huang, T. M.; Kecman, V.; Kopriva, I. 2006. Kernel based algorithms for mining huge data sets: supervised, semi-supervised, and unsupervised learning, Studies in computational intelligence, Vol. 17. Springer. $260 \mathrm{p}$.

Hughes, B. P.; Fattuhi, N. I. 1989. Reinforced steel and polypropylene fibre concrete corbel tests, The Structural Engineer 67(4): 68-72.

Hussein, A.; Rashid, I.; Benmokrane, B. 2004. Two-way concrete slabs reinforced with GFRP bars, in Proc. of the $4^{\text {th }}$ International Conference on Advanced Composite Materials in Bridges and Structures, July 2004, Calgary, Alberta, 20-23.

Kromanis, R.; Kripakaran, P. 2014. Predicting thermal response of bridges using regression models derived from measurement histories, Computers \& Structures 136: 64-77. http://dx.doi.org/10.1016/j.compstruc.2014.01.026

Lee, J.-H.; Yoon, Y.-S.; Cook, W. D.; Mitchell, D. 2009. Improving punching shear behavior of glass fiber-reinforced polymer reinforced slabs, ACI Structural Journal 106(4): $427-434$. 
Li, H.-S.; Lu, Z.-Z. 2007. Support vector regression for structural reliability analysis, Acta Aeronautica Et Astronautica Sinica 28: 94.

Liu, C.-C.; Liu, J. 2010. Damage identification of a long-span arch bridge based on support vector machine, Zhendong yu Chongji [Journal of Vibration and Shock] 29: 174-178.

Matthys, S.; Taerwe, L. 2000. Concrete slabs reinforced with FRP grids. II: punching resistance, Journal of Composites for Construction 4(3): 154-161.

http://dx.doi.org/10.1061/(ASCE)1090-0268(2000)4:3(154)

Muhammad, A. 1998. Behavior and strength of high-strength fiber reinforced concrete corbels subjected to monotonic or cyclic (repeated) loading. $\mathrm{PhD}$ thesis. University of Technology, Baghdad, Iraq.

Mukherjee, S.; Vapnik, V. 1999. Support vector method for multivariate density estimation. Center for Biological and Computational Learning, Department of Brain and Cognitive Sciences, MIT. CBCL. 170 p.

Nghiep, V. H. 2011. Shear design of straight and haunched concrete beams without stirrups. Berlin: Shaker Verlag $\mathrm{GmbH}$, Germany. 278 p.

Nguyen-Minh, L.; Rovňák, M. 2012. Punching shear resistance of interior GFRP reinforced slab-column connections, Journal of Composites for Construction 17(1): 2-13. http://dx.doi.org/10.1061/(ASCE)CC.1943-5614.0000324

Nilson, A.; Darwin, D.; Dolan, C. 2011. Design of concrete structures. 14th ed. New York: McGraw Hill, USA. 816 p.

Ospina, C. E.; Alexander, S. D.; Cheng, J. R. 2003. Punching of two-way concrete slabs with fiber-reinforced polymer reinforcing bars or grids, ACI Structural Journal 100(5): 589-598.

Pal, M.; Deswal, S. 2011. Support vector regression based shear strength modelling of deep beams, Computers \& Structures 89(13): 1430-1439. http://dx.doi.org/10.1016/j.compstruc.2011.03.005

Raghavendra, N. S.; Deka, P. C. 2014. Support vector machine applications in the field of hydrology: a review, Applied Soft Computing 19: 372-386.

http://dx.doi.org/10.1016/j.asoc.2014.02.002

Ranković, V.; Grujović, N.; Divac, D.; Milivojević, N. 2014. Development of support vector regression identification model for prediction of dam structural behaviour, Structural Safety 48: 33-39.

http://dx.doi.org/10.1016/j.strusafe.2014.02.004

Samui, P.; Kim, D. 2012. Utilization of support vector machine for prediction of fracture parameters of concrete, Computers \& Concrete 9: 215-226.

http://dx.doi.org/10.12989/cac.2012.9.3.215

Satpal, S. B.; Khandare, Y.; Guha, A.; Banerjee, S. 2013. Structural health monitoring of a cantilever beam using support vector machine, International Journal of Advanced Structural Engineering (IJASE) 5(2): 1-7.

Siddique, R. 2008. Modeling properties of self-compacting concrete: support vector machines approach, Computers \& Concrete 5: 461-473. http://dx.doi.org/10.12989/cac.2008.5.5.461

Shengguo, W.; Junbo, G. 2007. Research on support vector machine's prediction of concrete strength, Industrial Construction, 2007-S1.

Shujian, Z.; Jiwei, L.; Jiquan, H. 2007. Application of principal component analysis and support vector machine in evaluating corrosion severity of reinforcing steel in concrete, Electronic Measurement Technology 9: 16-18.

Sobhani, J.; Khanzadi, M.; Movahedian, A. 2013. Support vector machine for prediction of the compressive strength of noslump concrete, Computers and Concrete 11(4): 337-350. http://dx.doi.org/10.12989/cac.2013.11.4.337

Sonebi, M.; Cevik, A. 2009. Prediction of fresh and hardened properties of self-consolidating concrete using neuro- fuzzy approach, Journal of Materials in Civil Engineering 21(11): 672-679.

http://dx.doi.org/10.1061/(ASCE)0899-1561(2009)21:11(672)

Sriraam, A.; Sekar, S.; Samui, P. 2012. Support vector machine modelling for the compressive strength of concrete, in Proceedings of the Eighth International Conference on Engineering Computational Technology, 2012, Stirlingshire, Scotland, 71. http://dx.doi.org/10.4203/ccp.100.71

Stefanou, G. D. 1983. Shear resistance of reinforced concrete beams with non-prismatic sections, Engineering Fracture Mechanics 18(3): 643-666. http://dx.doi.org/10.1016/0013-7944(83)90057-7

Sun, Q.; Gao, L.; Zhao, H. 2013. Prediction for high volume fly ash concrete strength based on LS-SVM, Journal of Liaoning Technical University (Natural Science) 7: 014.

Tena-Colunga, A.; Archundia-Aranda, H. I.; González-Cuevas, Ó. M. 2008. Behavior of reinforced concrete haunched beams subjected to static shear loading, Engineering Structures 30(2): 478-492.

http://dx.doi.org/10.1016/j.engstruct.2007.04.017

Tesfamariam, S.; Liu, Z. 2010. Earthquake induced damage classification for reinforced concrete buildings, Structural Safety 32(2): 154-164.

http://dx.doi.org/10.1016/j.strusafe.2009.10.002

Theodorakopoulos, D. D.; Swamy, N. 2007. Analytical model to predict punching shear strength of FRP-reinforced concrete flat slabs, ACI Structural Journal 104(3): 256-266.

Tripathi, S.; Srinivas, V. V.; Nanjundiah, R. S. 2006. Downscaling of precipitation for climate change scenarios: a support vector machine approach, Journal of Hydrology 330(3-4): 621-640. http://dx.doi.org/10.1016/j.jhydrol.2006.04.030

Vapnik, V. 2000. The nature of statistical learning theory. Berlin: Springer. $314 \mathrm{p}$. http://dx.doi.org/10.1007/978-1-4757-3264-1

Wang, L. (Ed.). 2005. Support vector machines: theory and applications. Studies in Fuzziness and Soft Computing, Vol. 177. Springer. 431 p.

Wang, Z.; Ding, D.; Zhang, Z. 2011. Study of support vector machine and its application in concrete strength prediction, Journal of University of South China (Science and Technology) 1, 006.

Wu, X.; Tanh, W.; Wu, X. 2012. Support vector machine based on hybrid kernel function, in Information Engineering and Applications, Lecture Notes in Electrical Engineering, Vol. 154, 127-133. http://dx.doi.org/10.1007/978-1-4471-2386-6_17

Xiang, R. 2009. Prediction of concrete carbonation depth based on support vector regression, in Third International IEEE Symposium on Intelligent Information Technology Application (IITA 2009), 21-22 November 2009, Nanvhang, China, 172-175. http://dx.doi.org/10.1109/IITA.2009.469

Xie, X.; Li, P.; Qin, H.; Liu, L.; Nobes, D. C. 2013. GPR identification of voids inside concrete based on the support vector machine algorithm, Journal of Geophysics and Engineering 10: 034002. http://dx.doi.org/10.1088/1742-2132/10/3/034002

Xu, C.; Yun, S.; Shu, Y. 2008. Concrete strength inspection conversion model based on SVM [J], Journal of Luoyang Institute of Science and Technology (Natural Science Edition) 2, 025 .

Yan, K.; Shi, C. 2010. Prediction of elastic modulus of normal and high strength concrete by support vector machine. Construction and Building Materials 24(8): 1479-1485. http://dx.doi.org/10.1016/j.conbuildmat.2010.01.006

Yan, K.; Xu, H.; Shen, G.; Liu, P. 2013. Prediction of splitting tensile strength from cylinder compressive strength of concrete by support vector machine, Advances in Materials Science and Engineering 2013, 597257. http://dx.doi.org/10.1155/2013/597257 
Yang, H.; Dong, Y. 2013. Modelling concrete strength using support vector machines, Applied Mechanics and Materials 438: 170-173. http://dx.doi.org/10.4028/www.scientific. net/AMM.438-439.170

Yang, S.; Fang, C. Q.; Yuan, Z. J. 2014. Study on mechanical properties of corroded reinforced concrete using support vector machines, Applied Mechanics and Materials 1556: $578-579$.

Yinfeng, D.; Yingmin, L.; Ming, L.; Mingkui, X. 2008. Nonlinear structural response prediction based on support vector machines, Journal of Sound and Vibration 311(3-5): 886-897. http://dx.doi.org/10.1016/j.jsv.2007.09.054

Yu, P.-S.; Chen, S.-T.; Chang, I. F. 2006. Support vector regression for real-time flood stage forecasting, Journal of Hydrology 328(3-4): 704-716.

http://dx.doi.org/10.1016/j.jhydrol.2006.01.021

Yuvaraj, P.; Ramachandra, A.; Iyer, N.; Sekar, S.; Samui, P. 2013. Support vector regression based models to predict fracture characteristics of high strength and ultra high strength concrete beams, Engineering Fracture Mechanics 98: 29-43. http://dx.doi.org/10.1016/j.engfracmech.2012.11.014

Zaghloul, A. 2003. Punching behavior of CFRP reinforced concrete flat plate, in Proceedings of the International Conference on Composites in Construction, 2003, Cosenza, Italy, $16-17$.

Zhang, Q. 2006. Behaviour of two-way slabs reinforced with CFRP bars. M. Eng. Memorial University of Newfoundland, Canada. No MR30530.
Zhang, J.; Sato, T. 2006. Non-linear hysteretic structural identification by utilizing on-line support vector regression, Doboku Gakkai Ronbunshuu A 62(2): 312-322. http://dx.doi.org/10.2208/jsceja.62.312

Zhang, J.; Sato, T.; Iai, S. 2006. Support vector regression for on-line health monitoring of large-scale structures, Structural Safety 28(4): 392-406. http://dx.doi.org/10.1016/j.strusafe.2005.12.001

Zhang, W.; Song, Z. 2012. Prediction of concrete corrosion in sulfuric acid by SVM-based method, in The $2^{\text {nd }}$ International Conference on Electronic \& Mechanical Engineering and Information Technology, 7 September 2012, Shenyang, China. Atlantis Press, 400-404.

Zhang, D.-F.; Liu, J.-X.; Xie, W. 2010a. Nondestructive testing for grouting quality in prestressed concrete T-beam based on SVM, Journal of Central South University (Science and Technology) 4: 057.

Zhang, M.-Y.; Chen, L.-M.; Yang, K.-J.; Chen, Y. 2010b. Pattern identification and test analysis of structural damage, Journal of Natural Disasters 4: 014.

Zhitao, L.; Hongming, H.; Shengli, Z. 2008. Research on support vector machine's prediction of concrete carbonization, in 2008 International Seminar on Business and Information Management, 19 December 2008, Wuhan, Hubei, China, 319-322.

Zhu, X. Q.; Hao, H. 2007. Structural damage detection using wavelet support vector machine, in 2007 Conference \& Exposition on Structural Dynamics (IMAC-XXV), 19-22 February 2007, Orlando, Florida, USA, 1009-10017.

\begin{abstract}
Abdulkadir ÇEVIK. PhD. Associate Professor at Civil Engineering Department, University of Gaziantep, Turkey. At present, he is a Vice Dean of Engineering Faculty. He published several articles focusing on soft computing techniques. His research interests include structural mechanics, soft computing and artificial intelligence.
\end{abstract}

Ahmet Emin KURTOĞLU. Teaching and Research Assistant at Zirve University, Gaziantep, Turkey. He is MSc degree holder of Civil Engineering Department. Also, he is a $\mathrm{PhD}$ candidate at Civil Engineering Department, University of Gaziantep. His research interests are mechanics of materials, fiber reinforced polymers, reliability analysis and soft computing.

Mahmut BILGEHAN. PhD. Associate Professor at Civil Engineering Department, Zirve University, Gaziantep, Turkey. He is the chair of Civil Engineering Department. His research interests are artificial intelligence, soft computing and reinforced concrete structures.

Mehmet Eren GÜLŞAN. Teaching and Research Assistant at University of Gaziantep, Gaziantep, Turkey. He is also a PhD candidate at Civil Engineering Department, University of Gaziantep. His research interests are mechanics of materials, steel fiber reinforced concrete, reliability analysis and soft computing.

Hasan M. ALBEGMPRLI. PhD candidate at Civil Engineering Department, University of Gaziantep. His research interests are mechanics of materials, fiber reinforced polymers, reliability analysis and haunched beams. 


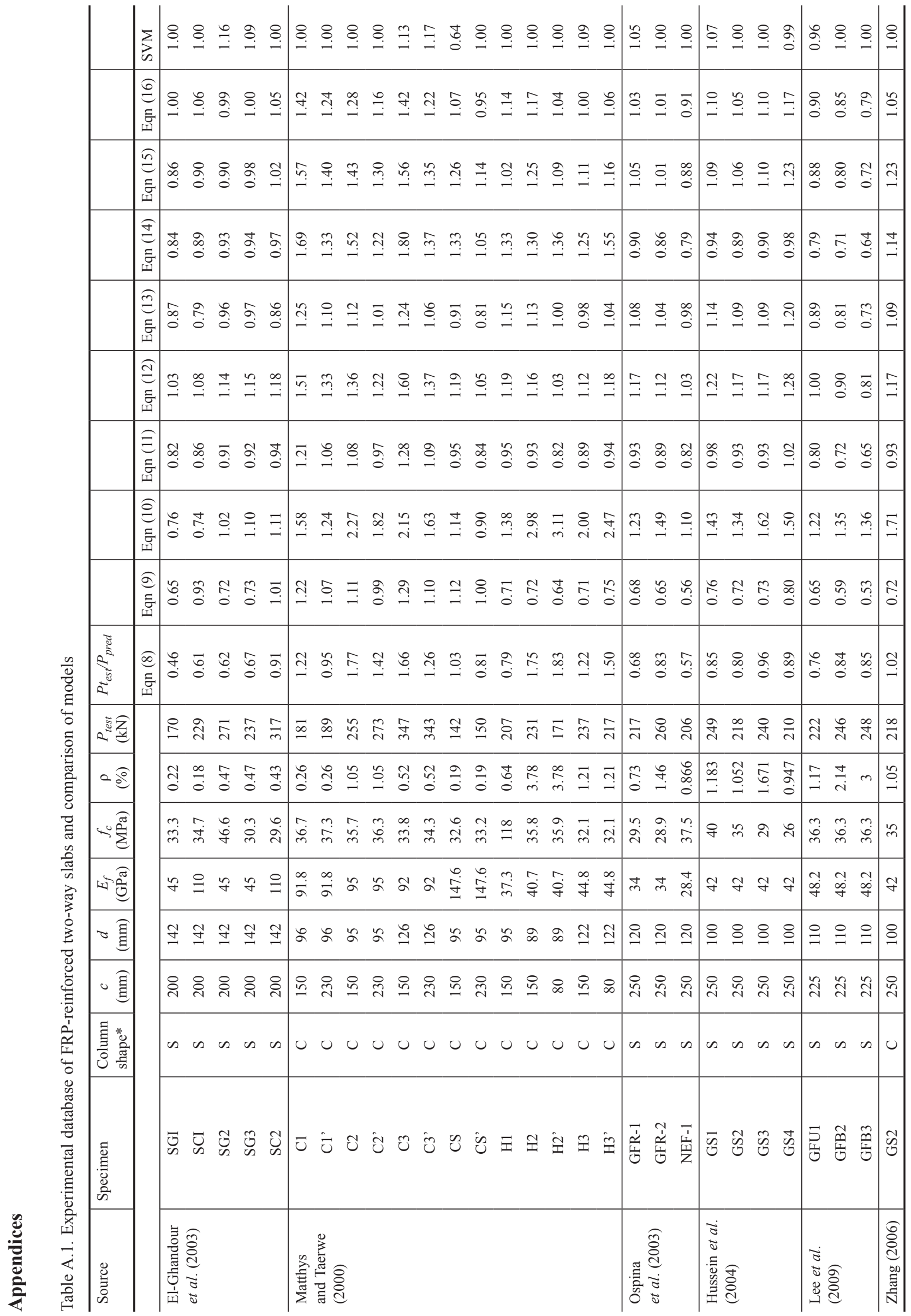




\begin{tabular}{|c|c|c|c|}
\hline & $\sum_{\substack{s \\
\infty}}^{1}$ & \& & 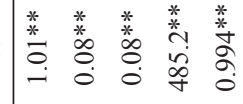 \\
\hline & $\begin{array}{l}6 \\
\stackrel{6}{0} \\
\vdots \\
\\
1\end{array}$ & 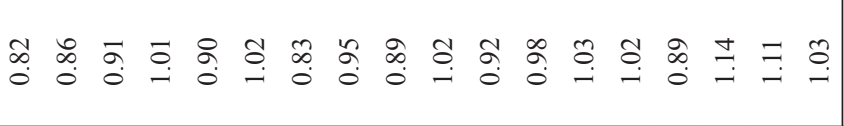 & 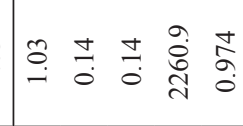 \\
\hline & 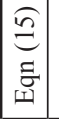 & 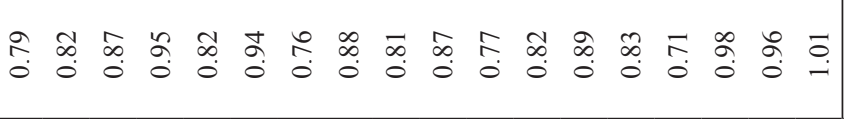 & 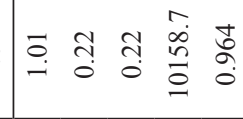 \\
\hline & 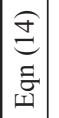 & 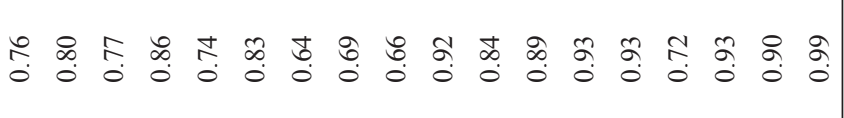 & 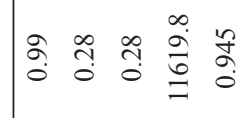 \\
\hline & 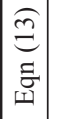 & 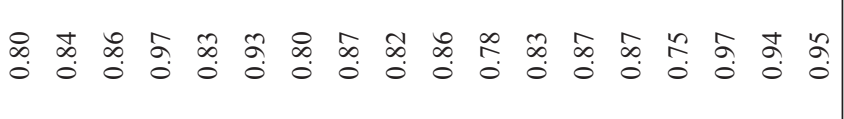 & 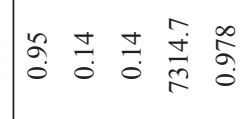 \\
\hline & 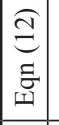 & 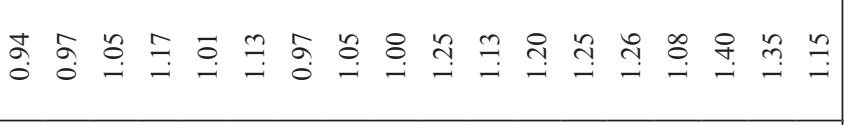 & 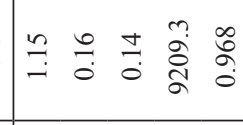 \\
\hline & $\begin{array}{l}\underset{\Xi}{\Xi} \\
\vdots \\
\text { 至 }\end{array}$ & 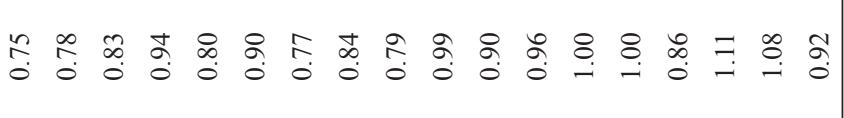 & 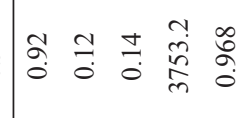 \\
\hline & 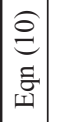 & 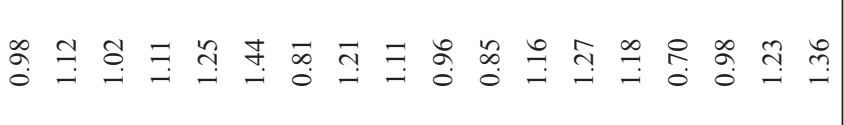 & 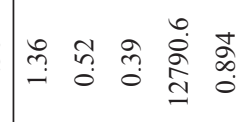 \\
\hline & $\begin{array}{c}\hat{0} \\
\vdots \\
\vdots \\
\text { ज्ञ }\end{array}$ & 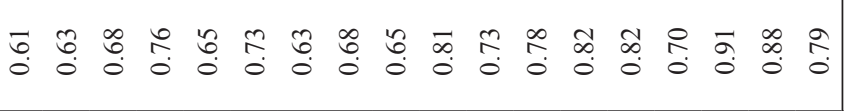 & 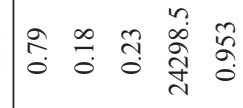 \\
\hline$\frac{\sqrt{3}}{5^{\frac{3}{2}}}$ & 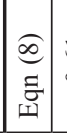 & 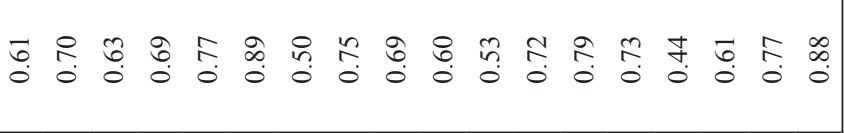 & 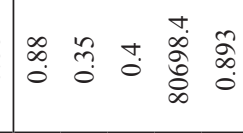 \\
\hline $2^{2}$ & & 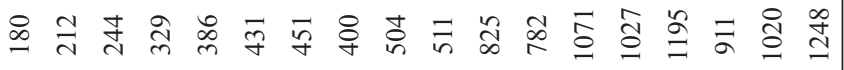 & \\
\hline$a @$ & & 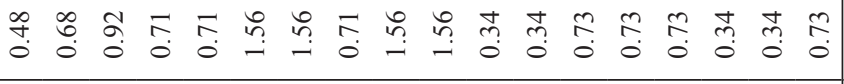 & \\
\hline$\sim \stackrel{\pi}{\Sigma}$ & & 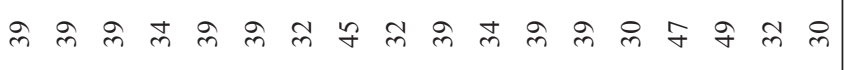 & \\
\hline 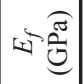 & & 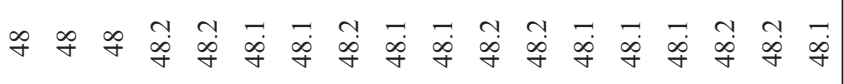 & \\
\hline ○夆 & & 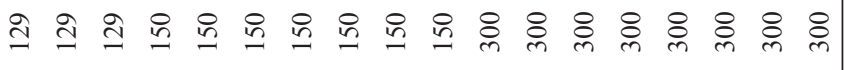 & \\
\hline 咱 & & ¿ి \& \& & \\
\hline 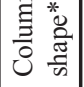 & & 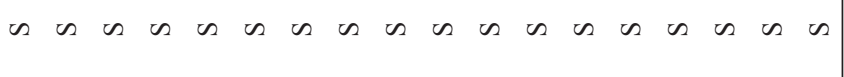 & \\
\hline 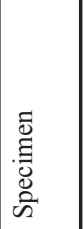 & & 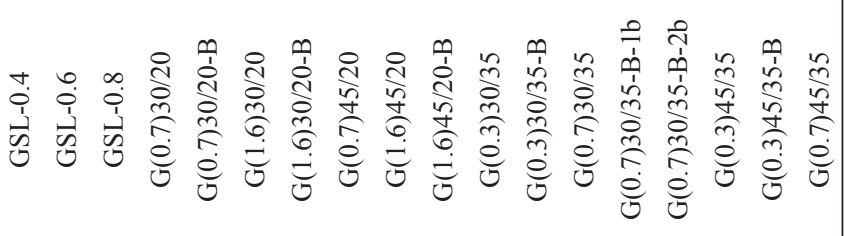 & \\
\hline$\stackrel{\circlearrowright}{\circlearrowright}$ & & 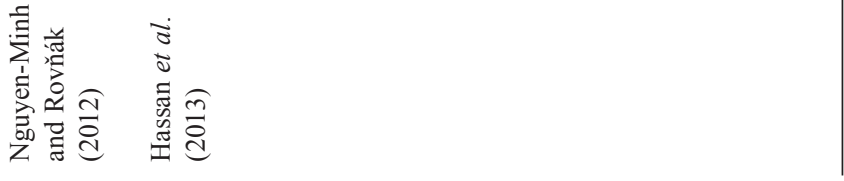 & 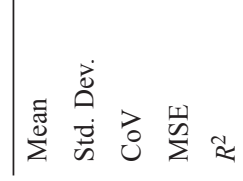 \\
\hline
\end{tabular}




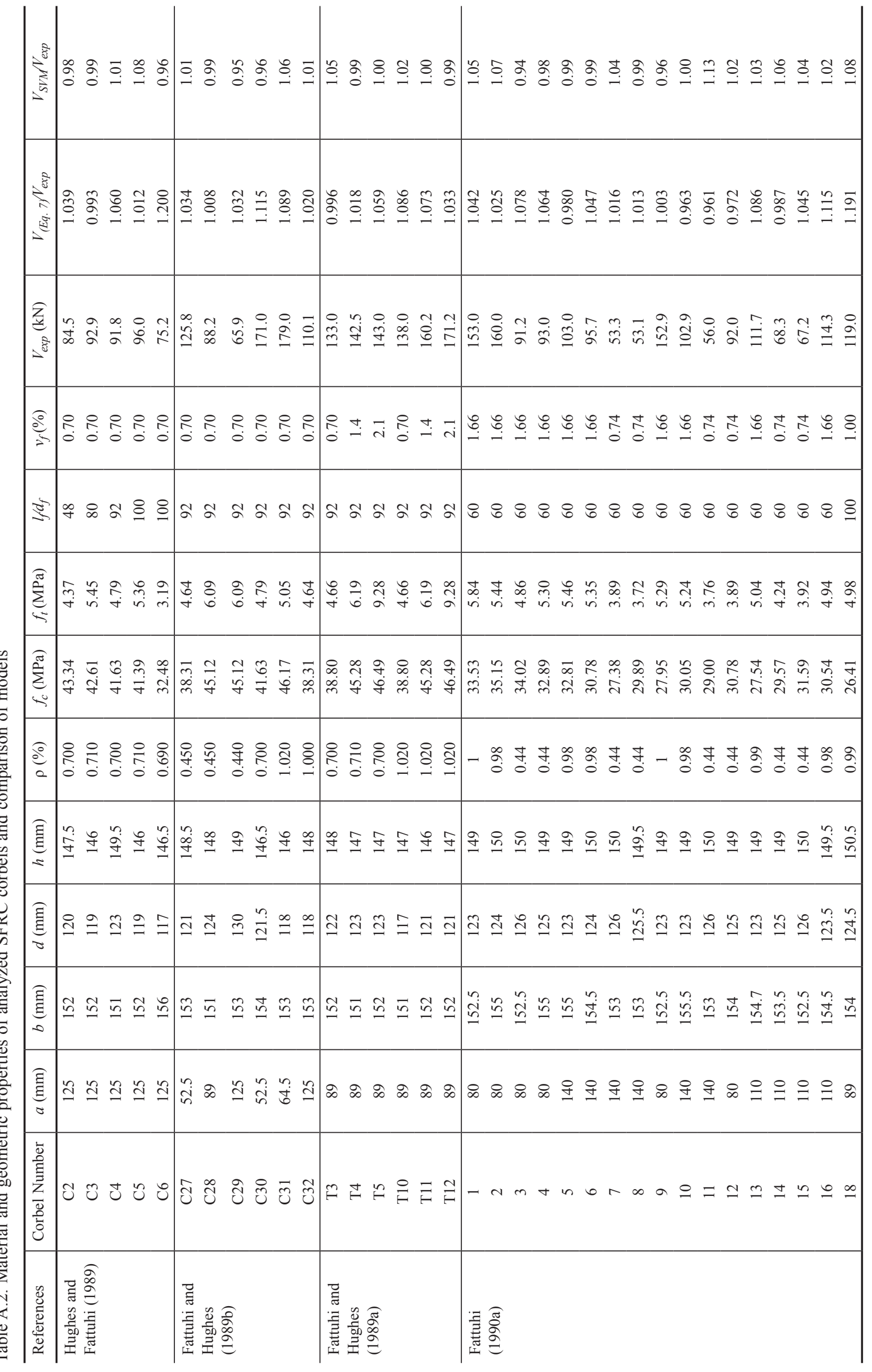




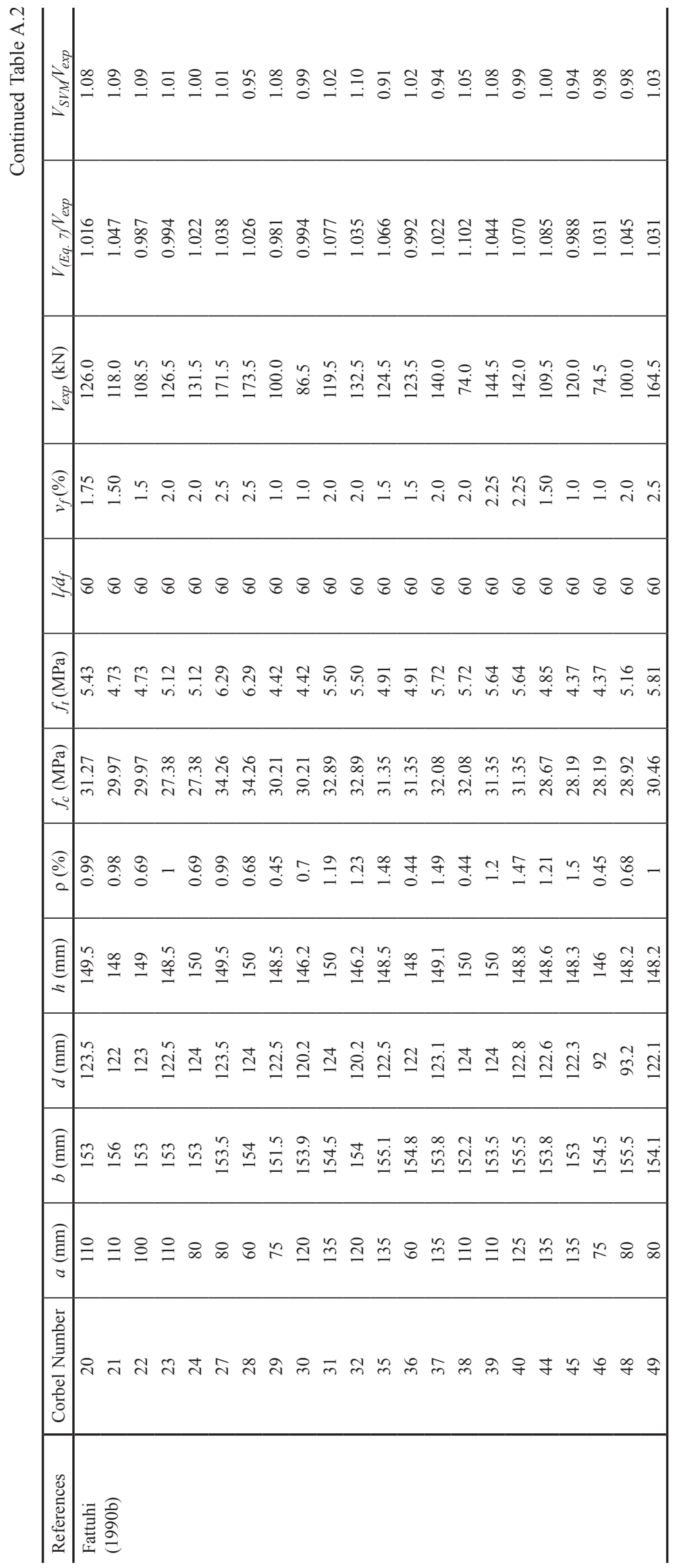




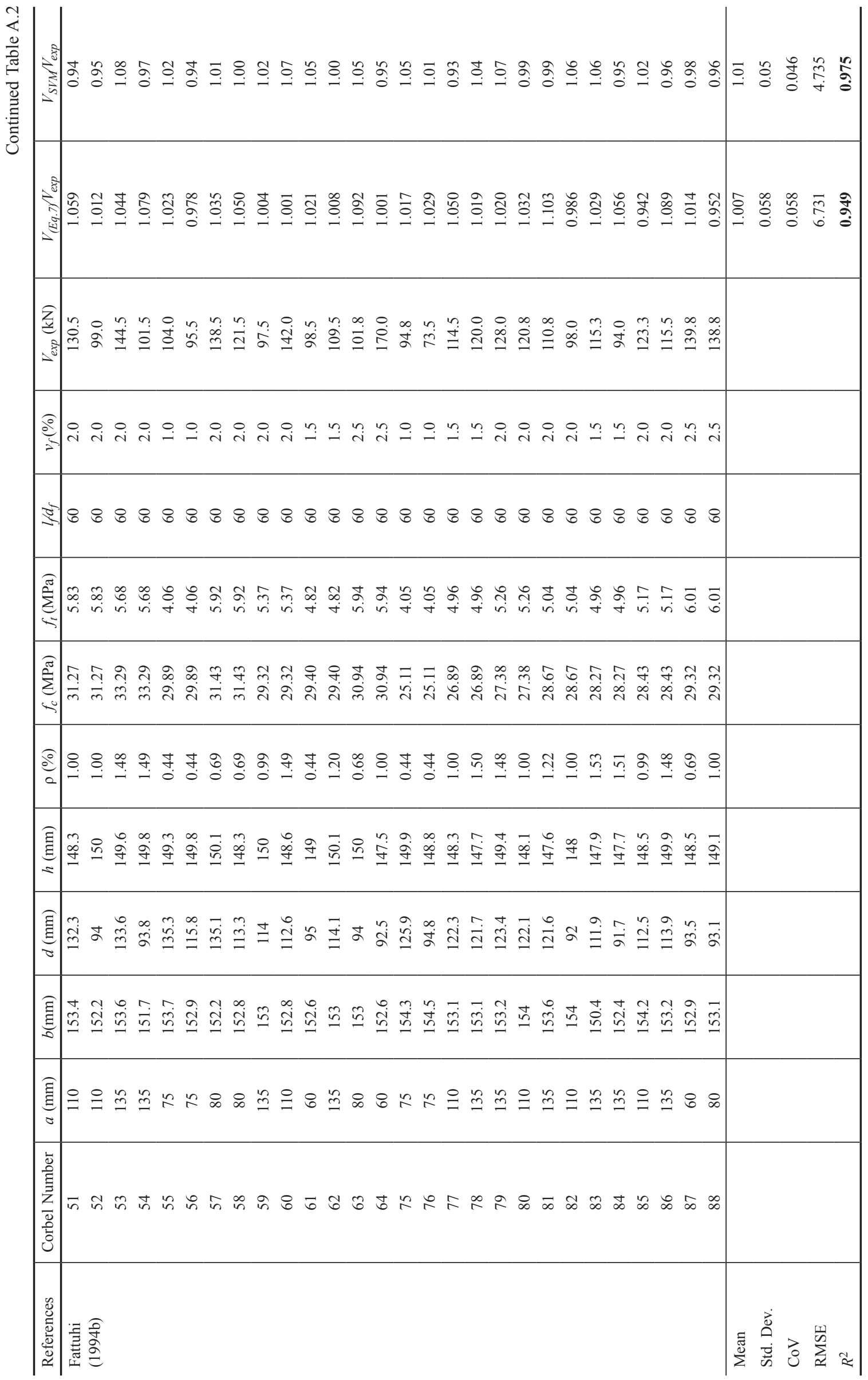


Table A.3. Material and geometric properties of analyzed RC haunched beams and comparison models

\begin{tabular}{|c|c|c|c|c|c|c|c|c|c|c|c|}
\hline Source & Specimen & $B(\mathrm{~cm})$ & $d_{s}(\mathrm{~cm})$ & $\alpha^{\mathrm{o}}$ & $\rho_{\mathrm{s}}^{*}$ & $\rho_{\mathrm{v}}{ }^{*}$ & $f_{c}(\mathrm{MPa})$ & $f_{y}(\mathrm{MPa})$ & $V_{\exp }(\mathrm{kN})$ & $V_{\text {pred }}(\mathrm{kN})$ & $V_{\text {pred }} / V_{\text {exp }}$ \\
\hline \multirow{21}{*}{$\begin{array}{l}\text { Debaiky } \\
\text { and Elniema } \\
(1982)\end{array}$} & $\mathrm{A} 2$ & 12 & 11 & 9.46 & 0.00198 & 0.03 & 20 & 461 & 58 & 58.02 & 1.00 \\
\hline & B3 & 12 & 11 & 9.46 & 0.00198 & 0.03 & 18.6 & 461 & 65.5 & 65.48 & 1.00 \\
\hline & B4 & 12 & 11 & 9.46 & 0.00198 & 0.03 & 21 & 461 & 101.5 & 101.51 & 1.00 \\
\hline & $\mathrm{C} 2$ & 12 & 11 & 9.46 & 0.00198 & 0.03 & 28.2 & 461 & 72 & 71.98 & 1.00 \\
\hline & D3 & 12 & 11 & 9.46 & 0.00396 & 0.03 & 29.6 & 461 & 69 & 68.98 & 1.00 \\
\hline & D4 & 12 & 11 & 9.46 & 0.00419 & 0.03 & 27.5 & 461 & 58.5 & 58.49 & 1.00 \\
\hline & F3 & 12 & 11 & 9.46 & 0.00235 & 0.019 & 21.5 & 461 & 44 & 44.01 & 1.00 \\
\hline & F4 & 12 & 11 & 9.46 & 0.00235 & 0.024 & 21 & 461 & 45.5 & 45.51 & 1.00 \\
\hline & $\mathrm{A} 3$ & 12 & 18.5 & 4.76 & 0.00198 & 0.03 & 17.8 & 461 & 78.5 & 78.53 & 1.00 \\
\hline & $\mathrm{C} 3$ & 12 & 18.5 & 4.76 & 0.00198 & 0.03 & 27.8 & 461 & 52 & 51.96 & 1.00 \\
\hline & A4 & 12 & 33.5 & -4.76 & 0.00198 & 0.03 & 22 & 461 & 51.3 & 51.30 & 1.00 \\
\hline & $\mathrm{C} 5$ & 12 & 33.5 & -4.76 & 0.00198 & 0.03 & 31.4 & 461 & 57.5 & 57.50 & 1.00 \\
\hline & E2 & 12 & 33.5 & -4.76 & 0.00314 & 0.032 & 33.5 & 461 & 75 & 75.04 & 1.00 \\
\hline & A5 & 12 & 41 & -9.46 & 0.00198 & 0.03 & 22.5 & 461 & 57 & 56.99 & 1.00 \\
\hline & B5 & 12 & 41 & -9.46 & 0.00198 & 0.03 & 20.6 & 461 & 78.5 & 78.48 & 1.00 \\
\hline & $\mathrm{C} 4$ & 12 & 41 & -9.46 & 0.00198 & 0.03 & 31.1 & 461 & 61 & 61.02 & 1.00 \\
\hline & D5 & 12 & 41 & -9.46 & 0.00396 & 0.03 & 28.9 & 461 & 65 & 65.02 & 1.00 \\
\hline & D6 & 12 & 41 & -9.46 & 0.00419 & 0.03 & 32.2 & 461 & 75 & 75.02 & 1.00 \\
\hline & E1 & 12 & 41 & -9.46 & 0.00314 & 0.032 & 34.8 & 461 & 95 & 94.94 & 1.00 \\
\hline & F1 & 12 & 41 & -9.46 & 0.00235 & 0.019 & 21.1 & 461 & 67 & 66.96 & 1.00 \\
\hline & $\mathrm{F} 2$ & 12 & 41 & -9.46 & 0.00235 & 0.024 & 20.8 & 461 & 70.5 & 70.52 & 1.00 \\
\hline \multirow{8}{*}{$\begin{array}{l}\text { Tena-Colunga } \\
\text { et al. (2008) }\end{array}$} & TASC1-0 & 22 & 41 & -3.07 & - & 0.0263 & 32.1 & 412 & 67.5 & 67.51 & 1.00 \\
\hline & TASC2-0 & 22 & 41 & -6.12 & - & 0.0308 & 29.5 & 412 & 60 & 59.99 & 1.00 \\
\hline & TASC3-0 & 22 & 41 & -9.13 & - & 0.0372 & 23.6 & 412 & 37.5 & 37.53 & 1.00 \\
\hline & TASC4-0 & 22 & 41 & -12.1 & - & 0.047 & 28.1 & 412 & 30 & 30.02 & 1.00 \\
\hline & TASC1-1 & 22 & 41 & -3.07 & 0.0025 & 0.0263 & 26.9 & 412 & 200 & 200.01 & 1.00 \\
\hline & TASC2-1 & 22 & 41 & -6.12 & 0.0025 & 0.0308 & 29.2 & 412 & 170 & 170.01 & 1.00 \\
\hline & TASC3-1 & 22 & 41 & -9.13 & 0.0025 & 0.0372 & 28.8 & 412 & 120 & 119.99 & 1.00 \\
\hline & TASC4-1 & 22 & 41 & -12.1 & 0.0025 & 0.047 & 21.1 & 412 & 80 & 79.98 & 1.00 \\
\hline \multirow{13}{*}{$\begin{array}{l}\text { Stefanou } \\
(1983)\end{array}$} & $\mathrm{B} 1-\mathrm{Ib}$ & 10 & 10 & 13.39 & - & 0.02 & 19.9 & 361 & 25 & 24.99 & 1.00 \\
\hline & B2-Ia & 10 & 15 & 8.13 & - & 0.013 & 19.9 & 361 & 26.5 & 26.46 & 1.00 \\
\hline & $\mathrm{B} 2-\mathrm{Ib}$ & 10 & 15 & 8.13 & - & 0.02 & 19.9 & 361 & 30 & 26.46 & 0.88 \\
\hline & B3-Ia & 10 & 10 & 13.39 & - & 0.013 & 15.7 & 361 & 27.5 & 25.02 & 0.91 \\
\hline & B3-Ib & 10 & 10 & 13.39 & - & 0.02 & 15.7 & 361 & 25 & 25.02 & 1.00 \\
\hline & B4-Ia & 10 & 15 & 8.13 & - & 0.013 & 15.7 & 361 & 26.5 & 32.51 & 1.23 \\
\hline & $\mathrm{B} 4-\mathrm{Ib}$ & 10 & 15 & 8.13 & - & 0.02 & 15.7 & 361 & 32.5 & 32.51 & 1.00 \\
\hline & B5- Ias & 10 & 10 & 13.39 & 0.0032 & 0.013 & 19.9 & 361 & 22.5 & 27.00 & 1.20 \\
\hline & B5-Ibs & 10 & 10 & 13.39 & 0.0032 & 0.02 & 19.9 & 361 & 27 & 27.00 & 1.00 \\
\hline & B6- Ias & 10 & 15 & 8.13 & 0.0032 & 0.013 & 19.9 & 361 & 29 & 29.06 & 1.00 \\
\hline & B6-Ibs & 10 & 15 & 8.13 & 0.0032 & 0.02 & 19.9 & 361 & 37.75 & 29.06 & 0.77 \\
\hline & B7- Ias & 10 & 10 & 13.39 & 0.0032 & 0.013 & 15.7 & 361 & 29 & 29.00 & 1.00 \\
\hline & B8- Ias & 10 & 15 & 8.13 & 0.0032 & 0.013 & 15.7 & 361 & 27.5 & 27.52 & 1.00 \\
\hline \multirow{5}{*}{$\begin{array}{l}\text { Nghiep } \\
(2011)\end{array}$} & $2 \mathrm{~L}$ & 20 & 20 & 3.95 & - & 0.0157 & 49.4 & 550 & 75 & 75.00 & 1.00 \\
\hline & $3 \mathrm{~L}$ & 20 & 15 & 5.91 & - & 0.0157 & 50.2 & 550 & 66.5 & 66.52 & 1.00 \\
\hline & $2 \mathrm{~K}$ & 20 & 24.3 & 3.95 & - & 0.0157 & 54 & 550 & 83.5 & 83.49 & 1.00 \\
\hline & $3 \mathrm{~K}$ & 20 & 20 & 6.71 & - & 0.0157 & 54 & 550 & 79.5 & 79.50 & 1.00 \\
\hline & $4 \mathrm{~K}$ & 20 & 15 & 10.01 & - & 0.0157 & 54 & 550 & 85 & 84.99 & 1.00 \\
\hline Mean & & & & & & & & & & & 1.00 \\
\hline Std. Dev. & & & & & & & & & & & 0.06 \\
\hline $\mathrm{CoV}$ & & & & & & & & & & & 0.06 \\
\hline MSE & & & & & & & & & & & 3.2 \\
\hline$R^{2}$ & & & & & & & & & & & 0.997 \\
\hline
\end{tabular}

